\title{
Topography of somatostatin gene expression relative to molecular progenitor domains during ontogeny of the mouse hypothalamus
}

\author{
Nicanor Morales-Delgado ${ }^{1,2+}$, Paloma Merchan ${ }^{2 \dagger}$, Sylvia M. Bardet ${ }^{2,3}$, José L. Ferrán ${ }^{2}$, Luis Puelles ${ }^{2}$ and \\ Carmen Díaz ${ }^{1}$ * \\ Department of Medical Sciences, School of Medicine, Regional Centre for Biomedical Research and Institute for Research in Neurological Disabilities, University of \\ Castilla-La Mancha, Albacete, Spain \\ 2 Department of Human Anatomy and Psychobiology, School of Medicine, University of Murcia, Murcia, Spain \\ ${ }^{3}$ UMR 1061, Unité de Génétique Moléculaire Animale, Institut National de la Recherche Agronomique, University of Limoges, Limoges, France
}

\section{Edited by:}

Fernando Martinez-Garcia, Universidad de Valencia, Spain

Reviewed by:

Nerea Moreno, University

Complutense of Madrid, Spain

Hans J. Ten Donkelaar, Radboud

University Nijmegen Medical Center,

Netherlands

\section{${ }^{*}$ Correspondence:}

Carmen Díaz, Department of Medical

Sciences, School of Medicine,

University of Castilla-La Mancha,

Almansa Street, 14, Albacete 02006,

Spain.

e-mail:carmen.diaz@uclm.es

${ }^{\dagger}$ Nicanor Morales-Delgado and Paloma Merchan have contributed equally to this work.
The hypothalamus comprises alar, basal, and floor plate developmental compartments. Recent molecular data support a rostrocaudal subdivision into rostral (terminal) and caudal (peduncular) halves. In this context, the distribution of neuronal populations expressing somatostatin (Sst) mRNA was analyzed in the developing mouse hypothalamus, comparing with the expression pattern of the genes Orthopedia (Otp), Distal-less 5 (D/x5), Sonic Hedgehog (Shh), and Nk2 homeobox 1 (Nkx2.1). At embryonic day 10.5 (E10.5), Sst mRNA was first detectable in the anterobasal nucleus, a Nkx2.1-, Shh-, and Otp-positive basal domain. By E13.5, nascent Sst expression was also related to two additional Otp-positive domains within the alar plate and one in the basal plate. In the alar plate, Sst-positive cells were observed in rostral and caudal ventral subdomains of the Otp-positive paraventricular complex. An additional basal Sstexpressing cell group was found within a longitudinal Otp-positive periretromamillary band that separates the retromamillary area from tuberal areas. Apart of subsequent growth of these initial populations, at E13.5 and E15.5 some Sst-positive derivatives migrate tangentially into neighboring regions. A subset of cells produced at the anterobasal nucleus disperses ventralward into the shell of the ventromedial hypothalamic nucleus and the arcuate nucleus. Cells from the rostroventral paraventricular subdomain reach the suboptic nucleus, whereas a caudal contingent migrates radially into lateral paraventricular, perifornical, and entopeduncular nuclei. Our data provide a topologic map of molecularly defined progenitor areas originating a specific neuron type during early hypothalamic development. Identification of four main separate sources helps to understand causally its complex adult organization.

Keywords: forebrain, hypothalamus, Sst, Otp, Dlk5, Nkx2.1, Shh, in situ hybridization

\section{INTRODUCTION}

The prosomeric model for the vertebrate forebrain proposes that the hypothalamus is a rostral forebrain entity, lying ventral to the telencephalon and rostral to the diencephalon (Puelles et al., 2004, 2007; Nieuwenhuys et al., 2008; Nieuwenhuys, 2009). Moreover, recent molecular data together with fate map analysis support a definition of the hypothalamus that excludes the preoptic area, considered nowadays a part of subpallial telencephalon (Bulfone et al., 1993; Rubenstein et al., 1998; Puelles et al., 2000; Cobos et al., 2001; Flames et al., 2007; Shimogori et al., 2010). In addition, differential expression of some developmental genes [e.g., Vax1 in Hallonet et al. (1998), Distal-less 5 (Dlx5), Six3 in Lagutin et al. (2003) and Puelles and Rubenstein (2003), Sim1, Orthopedia (Otp), Tbr1 in Puelles et al. (2004) and Bardet (2007), Sim1, Lhx6, Lhx8, Lhx9, Nkx6.2, Foxb1 in Shimogori et al. (2010)] support with their presence or absence, or with a dimensional change in their expression domain, a rostrocaudal subdivision of the hypothalamus into two transverse regions recently called terminal (rostral) and peduncular (caudal) hypothalamus [Allen Developing Mouse Brain Atlas ${ }^{1}$ (reference atlas done by Luis Puelles)]. Such a subdivision was already contemplated in earlier sources (Puelles and Rubenstein, 2003; Bardet, 2007; Nieuwenhuys, 2009). The same markers plus additional ones [e.g., $N k 2$ homeobox 2 (Nkx2.2), Sonic Hedgehog (Shh), Nk2 homeobox 1 (Nkx2.1)] also support a dorsoventral regionalization of the hypothalamus in alar, basal, and floor longitudinal subdivisions (Puelles and Rubenstein, 2003; Puelles et al., 2004; Bardet, 2007; Shimogori et al., 2010). The peduncular hypothalamus contains the dorsoventrally coursing lateral and medial forebrain bundles and the fornix. Thus, several genes regionalize dorsoventrally and caudo-rostrally the hypothalamus, previously and in parallel to cell differentiation in the mantle. For instance, at early stages of hypothalamic development, expression of Paired box 6 (Pax6) is restricted to the alar plate, whereas Shh and $N k x 2.1$ expression characterizes the basal plate, and $N k x 2.2$

${ }^{1}$ www.developingmouse.brain-map.org 
signal appears in a longitudinal band that overlaps the alar/basal boundary (reviewed in Puelles et al., 2004). Furthermore, the alar hypothalamus is subdivided longitudinally into a ventral domain called subparaventricular area $(\mathrm{SPa})$, characterized by $D l x$ and Arx gene expression, and a dorsal domain representing the classic paraventricular area $(\mathrm{Pa})$, which is an Otp-and Single-minded 1 (Sim1)-expressing domain (Puelles and Rubenstein, 2003; Bardet et al., 2008; Shimogori et al., 2010).

The differentiation of the hypothalamic hormone-producing neurons implicates a complex hierarchy of genetic interactions among transcription factors that sequentially define each phenotype. Such networks of transcription factors have been partially characterized in cells that populate neurosecretory hypothalamic nuclei such as the anterior periventricular area, the paraventricular nucleus and the supraoptic nucleus, all of them derived from the alar $\mathrm{Pa}$, or the arcuate nucleus (Arc), a separate basal plate derivative. Otp and Sim1/2 are key genes in the proliferation and differentiation of the precursors of cell types producing somatostatin (STT), thyrotropin-releasing hormone, corticotrophin-releasing hormone, arginine vasopressin or oxytocin in the anterior periventricular area, the paraventricular nucleus, and the supraoptic nucleus (Acampora et al., 1999, 2000; Goshu et al., 2004). Moreover, the homeobox-containing transcription factors NKX2.1 and OTP are jointly essential for the specification of SST-producing cells at the Arc (Acampora et al., 1999; Wang and Lufkin, 2000; reviewed by Caqueret et al., 2005).

Somatostatin (also known as somatotropin-release inhibiting factor) is a peptide that was first identified from bovine hypothalamic extracts, which plays an inhibitory role in the secretion of growth hormone (Brazeau et al., 1973) and thyroid-stimulating hormone (Vale et al., 1977) from anterior pituitary cells. In the adult hypothalamus, SST neurons of the anterior periventricular area and the paraventricular nucleus project to the median eminence (ME) and release the peptide into local capillaries; subsequently it reaches the anterior pituitary through the portal vasculature and exerts there its inhibiting neuroendocrine action. Other hypothalamic SST neurons have been located in the Arc, the suprachiasmatic area and the ventromedial hypothalamic nucleus (VMH; Johansson et al., 1984; Cotter and Laemle, 1987). Apart from the hypothalamic locations, STT has a wide distribution in other brain regions such as the amygdala, preoptic area, hippocampus, striatum, cerebral cortex, olfactory regions, and brainstem, where it acts as a neurotransmitter or neuromodulator (Viollet et al., 2008). STT and its receptors have also been implicated in brain development (Yacubova and Komuro, 2002; Le Verche et al., 2009).

In the present work, an attempt was made to analyze in detail the early spatiotemporal developmental distribution of Sst across distinct molecular subdivisions (progenitor areas) of the mouse hypothalamus, using in situ hybridization. To this end, the location of Sst-expressing cell was analyzed in relation to the signal of transcription factor genes such as Otp, Dlx5, Shh, and Nkx2.1 from embryonic day 9.5 (E9.5) to 15.5 (E15.5). Our data therefore refer exclusively to early differentiating Sst neurons, which show a wider distribution than was reported in previous ontogenetic studies (Shiosaka et al., 1982; Bendotti et al., 1990). There are at least four separate early sources of Sst cells, and our results suggest the occurrence of early radial and tangential migrations of
Sst cells within the hypothalamus. It should be noted that we do not address late differentiating hypothalamic Sst cell populations, which essentially become observable at late embryonic stages (after E18.5) and postnatally.

\section{MATERIALS AND METHODS ANIMALS}

All protocols involving care and use of laboratory animals were conformed to normative standards of the European Community (86/609/EEC) and the Spanish Government (Royal Decree, 1201/2005; Law 32/2007). Swiss albino mice from embryonic days 9.5 (E9.5) to 15.5 were used. For timing pregnancy, the day when vaginal plugs were detected was considered as day 0.5 of gestation (E0.5). For every embryonic age, we examined three to five mouse embryos.

\section{TISSUE PROCESSING}

Embryos were quickly removed from pregnant mice and the heads were immediately fixed by immersion in cold $4 \%$ paraformaldehyde in $0.1 \mathrm{M}$ phosphate buffered saline (PBS, pH 7.4). Afterward, the dissected brains were post-fixed overnight at $4^{\circ} \mathrm{C}$ in the same fixative, and then transferred to $30 \%$ sucrose in $0.1 \mathrm{M} \mathrm{PBS}$ for $24 \mathrm{~h}$ at $4^{\circ} \mathrm{C}$. Finally, they were embedded in $15 \%$ gelatin/20\% sucrose and frozen in isopentane at $-55^{\circ} \mathrm{C}$. Parallel series of sagittal and transversal sections were cut on a cryostat $20 \mu \mathrm{m}$-thick and mounted onto Superfrost-plus slides (Menzel-Gläser, Braunschweig, Germany).

\section{RT-PCR}

Sst and Dlx5 cDNA fragments were obtained by RT-PCR. RNA was extracted from fresh dissected brains of Mus musculus embryos at stages E10.5, 12.5, and 14.5 using Trizol reagent (10296-028, Invitrogen). The RNA was treated with DNase I (18068-015, Invitrogen) for $15 \mathrm{~min}$ at room temperature (RT), and then the enzyme was inactivated at $65^{\circ} \mathrm{C}$. The RNA was retro-transcribed into single-stranded cDNA with Superscript II reverse transcriptase and oligo dT anchored primers (11904-018, SuperScript First-Strand Synthesis System for RT-PCR; Invitrogen). The resulting first-strand cDNA $(0.5 \mu$ l of the reverse transcription reaction) was used as a template for PCR, performed with Taq polymerase (M8305, Promega). PCR conditions were as follows: 5 min at $94^{\circ} \mathrm{C}$, then 35 cycles $(30 \mathrm{~s}$ at $94^{\circ} \mathrm{C}$, plus $1 \mathrm{~min}$ at $\mathrm{Tm}$ temperature $-58^{\circ} \mathrm{C}$, and $1 \mathrm{~min}$ at $72^{\circ} \mathrm{C}$ ), followed by $10 \mathrm{~min}$ at $72^{\circ} \mathrm{C}$. The PCR products were cloned into pGEM-T Easy Vector (Promega) and sequenced (SAI, University of Murcia). Primers: MSstF: 5'-CTGAAGGAGACGCTACCGAAG-3'; MSstR: 5'-TCAATTTCTAATGCAGGGTCAA-3'; MDlx5F: 5'TAGACCAGAGCAGCTCCACA-3'; MDlx5R: 5'-GGCACCATTG ATAGTGTCCA-3'.

\section{IN SITU HYBRIDIZATION AND IMMUNOHISTOCHEMISTRY}

Sense and antisense digoxigenin-labeled riboprobes for mouse $D l \times 5$, $N k x 2.1, O t p$, Shh, and Sst were generated by in vitro transcription using $1 \mu \mathrm{g}$ of template, digoxigenin-11-UTP (Roche Diagnostics S.L., Applied Science, Barcelona, Spain), and specific polymerases (Promega). Plasmid information is provided in Table 1.

In situ hybridization experiments were performed as described by Hidalgo-Sánchez et al. (2005). Hybridizations were carried out overnight at $72^{\circ} \mathrm{C}$ (for $\mathrm{Otp}$ at $68^{\circ} \mathrm{C}$ ). Once hybridization 
Table 1 | Characteristics of the gene probes used for ISH.

\begin{tabular}{llcll}
\hline Gene & NCBI accession no. & Size (bp) & Position & Laboratory \\
\hline DIx5 & NM_010056.2 & 1180 & $106-1285$ & Present results \\
Nkx2.1 & NM_009385.2 & 2216 & $597-2813$ & Rubenstein J.L.R. \\
Otp & NM_011021.2 & 412 & $179-592$ & Simeone A. \\
Shh & NM_009170.2 & 643 & $442-1084$ & McMahon A. \\
Sst & NM_009215 & 556 & $6-561$ & Present results \\
\hline
\end{tabular}

was complete, slides were washed under stringent conditions. The probes were detected with an alkaline phosphatase-coupled anti-digoxigenin antibody using nitroblue tetrazolium/5-bromo4-chloro-3-indolyl phosphate (NBT/BCIP; Roche) for visualization. Exposure times ranged between 1 and 2 days. Sense probes were tested as negative controls and gave no specific signals (data not shown).

The immunohistochemical protocol was described in detail elsewhere (Bardet et al., 2006). The dilution of the polyclonal antiserum against rat NKX2.1 (TTF-1; Biopat Immunotechnologies, Caserta, Italy; no. PA 0100) was 1:1000. After washes, the sections were incubated with biotinylated goat anti-rabbit (Vector Laboratories, CA, USA; 1:200) followed by a streptavidin-peroxidase complex (Vectastain-ABC kit; Vector Laboratories), applied for $1 \mathrm{~h}$ at room temperature. Peroxidase activity was developed with $0.03 \%$ 3,3'-diaminobenzidine (Sigma; St Louis; MO, USA), plus 0.003\% hydrogen peroxidase. We verified the specificity of the antibody by performing parallel control experiments, omitting the primary antibody (data not shown). After hybridization and immunohistochemical labeling, the slides were washed in PBS, air dried and coverslipped with CYTOSEAL ${ }^{\mathrm{TM}} 60$ (Thermo).

\section{IMAGING}

Image acquisition of entire slides was carried out with a ScanScope CS digital slide scanner (Aperio Technologies, USA). After scanning, images of adjacent sections were captured by using the software ImageScope. Contrast and focus of singles images were enhanced, artificially pseudocolored (from blue to red) and superimposed using Adobe Photoshop CS3 (Adobe Systems Inc., San José, CA, USA).

\section{RESULTS}

\section{PRELIMINARY REMARKS ON HYPOTHALAMIC ORGANIZATION}

In order to map Sst mRNA expression and to identify different structures in the developing hypothalamus, we have used the updated prosomeric model of the vertebrate forebrain, developed by Luis Puelles for the Allen Developing Mouse Brain Atlas². In this model, the hypothalamus is understood as a portion of the secondary prosencephalon (separated from the classic "diencephalon"). It lies rostral to the diencephalon proper (prethalamus, thalamus, and pretectum) and ventral to the preoptic and innominate/diagonal telencephalic regions (see also Puelles, 1995, 2001; Puelles and Rubenstein, 2003; Puelles et al., 2004; Flames et al., 2007). Figure 1 summarizes the general position of

${ }^{2}$ http://www.developingmouse.brain-map.org/ the hypothalamus, its subdivisions, and major landmark nuclei according to the updated prosomeric model. The hypothalamus is subdivided dorsoventrally into alar, basal, and floor plate developmental components, and a transverse intrahypothalamic limit divides it rostrocaudally into two transverse regions denominated terminal hypothalamus and peduncular hypothalamus in the model (THy; PHy; Figures 1A-C; see also Puelles and Rubenstein, 2003; Puelles et al., 2007; Nieuwenhuys et al., 2008). The model includes a novel subdivision and terminology for the hypothalamic basal plate proposed in preliminary form by Bardet (2007) and further developed in the Allen Developing Mouse Brain Atlas ${ }^{3}$. There is a fundamental dorsoventral division of the basal plate into tuberal/ retrotuberal and mamillary/retromamillary regions, each of which has additional subdivisions (Tu/RTu, M/RM; Figure 1B). The alar plate is also divided into the $\mathrm{Pa}$ (dorsal) and the $\mathrm{SPa}$ (ventral; $\mathrm{Pa}$, SPa; Figure 1B; Bardet, 2007; Puelles et al., 2007). The Pa forms basically magnocellular and parvocellular neurosecretory populations of the supraopto-paraventricular complex, whereas the SPa forms mainly the suprachiasmatic nucleus, the anterior hypothalamic nucleus, and the subparaventricular zone. The dorsal border of the Pa defines the hypothalamic-telencephalic boundary (Figure 1A), which coincides with a plane separating the telencephalic stria terminalis tract from the non-telencephalic stria medullaris tract. All these dorsoventral alar and basal subdivisions are constituted by terminal (THy) and peduncular (PHy) moieties. The areas so delimited are considered independent progenitor areas, within which specific neuronal cell populations are born, forming characteristic nuclei (Figure 1B).

As markers of the fundamental hypothalamic subdivisions, helping us to localize the Sst-positive cells more precisely, we compared the expression pattern of transcription factors such as Otp (Pa and perimamillary/periretromamillary-PM/PRM-areas), Dlx5 (SPa and Tu/RTu areas), Shh and Nkx2.1 (basal plate in general; Figures 1C and 2). Between E10.5 and E15.5, the well-known separate paraventricular and perimamillary domains expressing Otp showed practically no overlap with telencephalic and hypothalamic Dlx5-positive domains (Figures 1C and 2A-C; Bardet et al., 2008). On the other hand, at these stages, $N k \times 2.1$ was expressed throughout the hypothalamic basal plate, as well as in the telencephalic subpallium (Figure 2D), while $S h h$ signal was found at the ventricular zone of the hypothalamic basal plate. Early on, Shh expression first appears restricted to the floor plate, but its domain soon expands into the adjacent basal plate and is secondarily downregulated in a basal subregion including rostral tuberal and mamillary subareas (Figure 2E; Martí et al., 1995). Variations of these patterns will be detailed below.

\section{AT E10.5 AND E11.5, THE EARLIEST Sst-P0SITIVE CELLS ARE RESTRICTED TO A ROSTRODORSAL BASAL PART OF THE TERMINAL HYPOTHALAMUS}

In addition to the marked Otp expression mentioned above as characterizing the Pa, less strongly marked Otp-positive cells were also found at E10.5 at the immature anterobasal nucleus ( $\mathrm{ABa}$ ), an $\mathrm{U}$-shaped terminal basal derivative distinguished across the midline of the rostrodorsal tuberal region ( $\mathrm{ABa}$; Figures $1 \mathrm{~B}$ and $3 \mathrm{~A}$ ). 


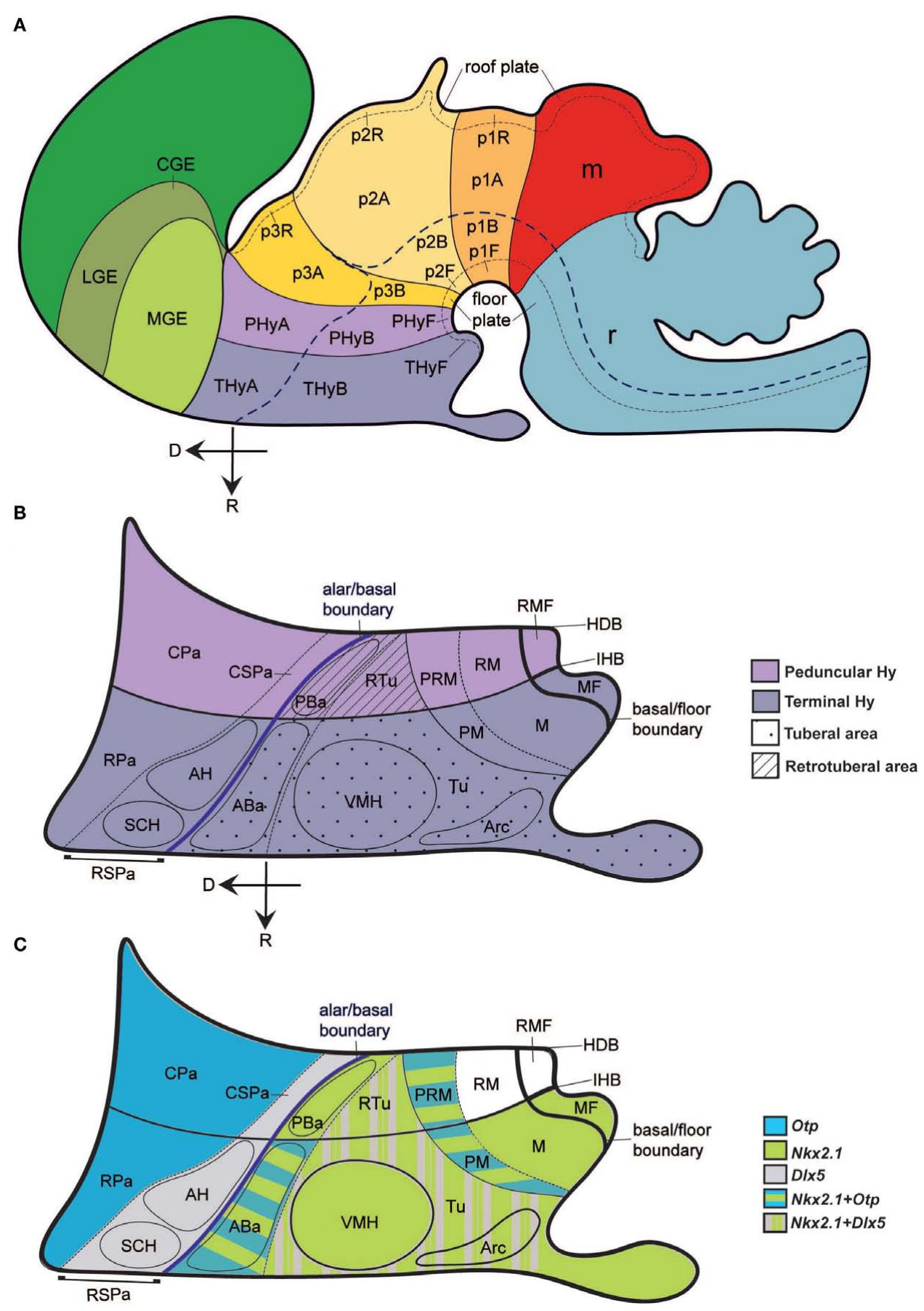

FIGURE 1 | Schematic model of the forebrain, illustrating hypothalamic position and main subdivisions. The rostral (R) and dorsal (D) spatial directions are indicated in (A,B). (A) Updated prosomeric model redrawn from the Allen Developing Mouse Brain Atlas (www.developingmouse.brain-map.org), showing the hypothalamo-telencephalic and hypothalamo-diencephalic boundaries, the alar-basal boundary and the main anteroposterior parts, the peduncular and terminal hypothalamic territories (PHy, THy). (B) Dorsoventral regional hypothalamic subdivisions across the color-coded PHy and THy (separated by the intrahypothalamic border; IHB). The thick blue line indicates the longitudinal alarbasal boundary. Alar territories are seen on the left [corresponding to PHyA and THyA in (A)], and basal territories on the right [PHyB and THyB in (A)]. Within the alar plate, a dashed line separates the rostral and caudal paraventricular subdomains
( $\mathrm{RPa}, \mathrm{CPa}$ ) from the rostral and caudal subparaventricular subdomains ( $\mathrm{RSPa}, \mathrm{CSPa})$. The RSPa contains the suprachiasmatic and anterior hypothalamic nuclei $(\mathrm{SCH}, \mathrm{AH})$. Within the basal plate, a thin continuous black line separates the tuberal and retrotuberal regions (Tu/RTu; dotted and striped fills, respectively) from the mamillary complex (undotted). A dashed line separates the dorsalTu/RTu subregion, occupied by the anterobasal and posterobasal nuclei ( $\mathrm{ABa}, \mathrm{PBa})$ from the main tuberal/ retrotuberal region, which contains the $\mathrm{VMH}, \mathrm{Arc}$, and $\mathrm{DMH}$ nuclei. Another dashed line divides the mamillary body into the dorsal perimamillary/periretromamillary regions (PM, PRM) and the ventral mamillary and retromamillary areas (M, RM). The corresponding parts of the hypothalamic floor lie underneath (MF, RMF). (C) Schematic reference gene expression patterns used in our mapping, represented upon the same diagram shown in (B). Striped color patterns imply overlap. 


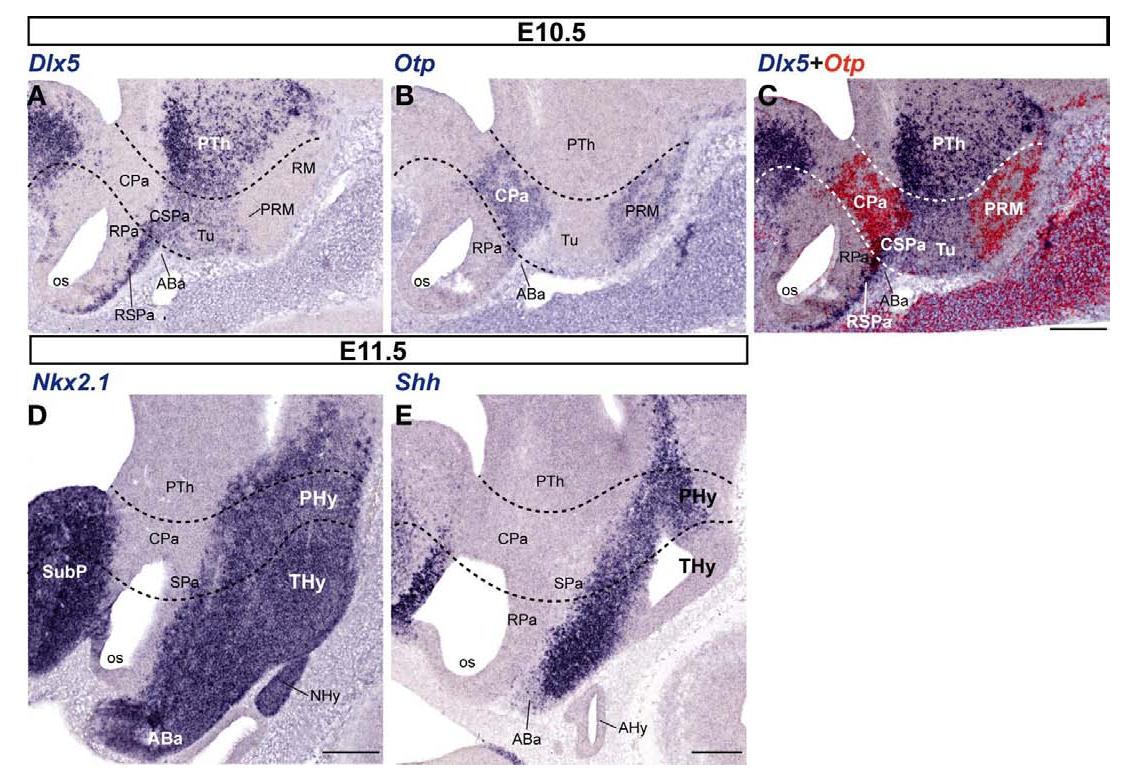

FIGURE 2 | Representative sagittal sections from E10.5 (A-C) and E11.5 (D,E) embryos, showing the expression domains of DIx5 (A), Otp (B), DIx5+ Otp (C; digital overlap with pseudocolor of A,B), $\mathbf{N k x 2 . 1}$ (D), and Shh (E). The transversal boundaries of the PHy and THy are indicated by dashed lines. Bars $=200 \mu \mathrm{m}$.

Altman and Bayer (1986) introduced the ABa term as a preferable alternative to the earlier "retrochiasmatic nucleus/area" name. It is apposite, since it is the rostral-most nucleus of the hypothalamic basal plate (Figure 3).

No Sst expression was detected at E9.5 (not shown). Sstexpressing neurons first appeared in the superficial stratum of the $\mathrm{ABa}$ at E10.5 (Figure 3) and their number was larger at E11.5 (not shown); this mantle locus shows two characteristic basal markers $N k x 2.1, S h h$ - which identify it as a part of the basal hypothalamus, and it always contains Otp-expressing cells that are more numerous than the Sst ones (Figures 3A-E,I-K allow comparison of these four markers); in contrast, the $D l \times 5$ marker is absent from the $\mathrm{ABa}$ at this stage, being restricted to the overlying SPa area (Figures $3 \mathrm{~F}-\mathrm{H}$ ). Shh expression was largely restricted to the ventricular/periventricular zone of the basal hypothalamus and a part of the preoptic area, and was only weakly present at the differentiating ABa cell group (ABa; Figures 3I,K).

\section{FIRST APPEARANCE OF Sst-POSITIVE CELLS IN THE HYPOTHALAMIC ALAR PLATE AT E12.5}

The first Sst-positive cells were found in the alar part of the PHy at E12.5. A sparse number of them were detected in the ventral part of the caudal paraventricular nucleus complex $(\mathrm{CPa})$, while the $\mathrm{CPa}$ is generally characterized by abundant Otp-expressing cells (Figures 4A-C). Some Sst cells at the borderline with the Dlx5positive SPa may have dispersed into it, also coinciding with scattered Otp-positive cells (Figures 4A-G). The Otp/Dlx5 (Pa/SPa) boundary is not a clearcut interface (Figures $4 \mathrm{~A}, \mathrm{D}, \mathrm{G}$ ).

However, at E12.5 the majority of Sst-positive cells were still concentrated at the rostrodorsal basal plate of the THy, within the superficial and intermediate strata of the $\mathrm{ABa}$ mantle zone. This tuberal domain also continued showing extensive Otp expression (Figures 4A-C), as well as $N k \times 2.1$ signal and ventricular Shh expression (Figures $4 \mathbf{H}-\mathbf{N}$ ).
Additionally, we observed that some Sst- and Otp-positive cells were distinguished superficially in the subjacent intermediate tuberal subdivision, also a Nkx2.1-positive domain, occupied by the ventromedial hypothalamic and arcuate nuclei (Figures 1B,C; arrowheads in Figures 4B,C,E,F,I,J,L,M). At this stage, the Otp-positive periretromamillary band (PRM) remains free of Sstcells, though there appear abundant such cells in the prethalamic tegmentum lying immediately caudal to it (PRM; PTh; Figures 4A-C).

\section{PROGRESS OF PRE-EXISTING ALAR AND BASAL SsT POPULATIONS AND APPEARANCE OF PERIMAMILLARY Sst CELLS AT E13.5}

At E13.5, more abundant Sst-positive cells were found in the alar plate, particularly at intermediate and superficial strata of the massively Otp-positive $\mathrm{Pa}$, and always localized mainly to its ventral part, over the SPa (Figures 5A-C). At the CPa domain, populations of Sst- and Otp-expressing cells are co-localized within the primordia of the lateral paraventricular nucleus (caudally, next to the hypothalamo-prethalamic boundary; LPa; Figures 5A-D) and a presumptive perifornical population (rostrally within $\mathrm{PHy}$, close to the intrahypothalamic boundary between PHy and THy; PFx, Figures 5A-D,L-O). The Otp-positive Pa domain showed a characteristic dorsal stream of migrating cells arching dorsolaterally into the telencephalon under the bottom of the interventricular foramen and connecting with the extended and medial amygdala (Fan et al., 1996; Wang and Lufkin, 2000; Puelles and Rubenstein, 2003; Garcia-Moreno et al., 2010); at E13.5 only a few Sst cells appeared mixed with this large Otp-positive cell stream (black arrowheads; Figures $\mathbf{5 M , N}$ ). These few elements need to be distinguished from the more numerous suprajacent Sst cells apparently associated to the subpallial bed nucleus striae terminalis complex, and, therefore, unrelated to the hypothalamus (white asterisk; BST; Figures $\mathbf{5 M , N}$ ). At the RPa, Otp cells start to invade the subpial stratum corresponding to the presumptive supraoptic 


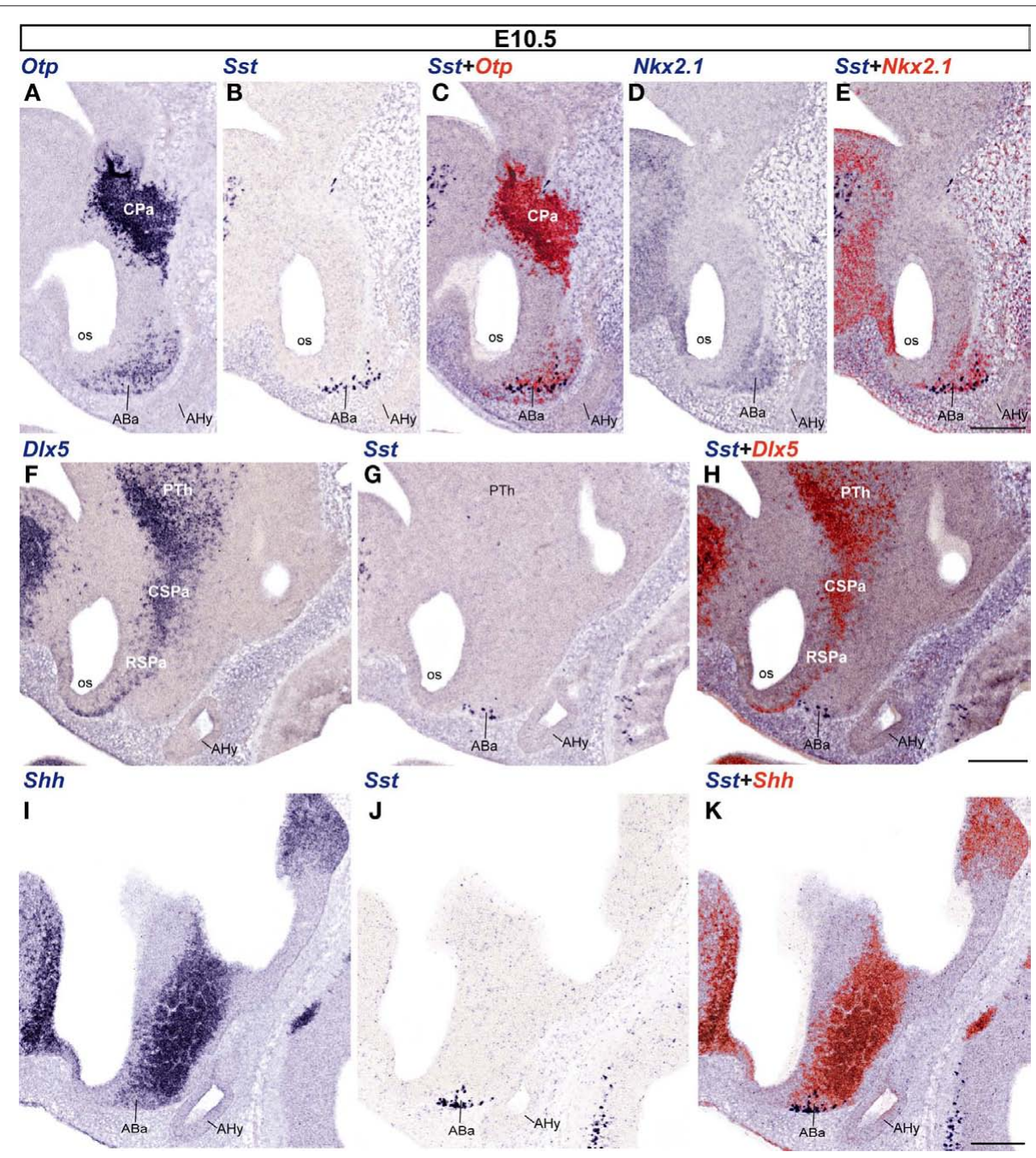

FIGURE 3 | Sagittal sections of E10.5 embryos taken at lateral (A-E), intermediate (F-H), and medial (I-K) levels, correlating the indicated reference markers with the presence of Sst-positive cells. Note the topographic coincidence of Sst signal with a larger surrounding population of Otp-positive cells. Bars $=200 \mu \mathrm{m}$.

and suboptic nuclei (SO; Figure 5A; we propose here to use "suboptic nucleus" - $\mathrm{SbO}$ - as a synonym of the confusing term "retrochiasmatic supraoptic nucleus," given that "retrochiasmatic" is in practice the contrary of "supraoptic" and wrongly refers to the chiasma, whereas the meaning of "suboptic" more clearly suggests the referred topography of this population relative to the optic tract). Suboptic Sst-positive cells were observed at this stage at the ventral part of the $\mathrm{RPa}$, in sagittal sections that pass lateral to the suprachiasmatic nucleus primordium ( $\mathrm{SbO}$; Figures $\mathbf{5 A - D}$ ). This zone is characterized by relatively dispersed Otp-positive cells and is partly intermixed with $D l x 5$-positive RSPa derivatives (Figures 5A-D).

The RSPa shows otherwise few dispersed Sst cells, whereas the caudal subparaventricular area (CSPa) displays a distinct thin band of such dispersed cells, which overlaps a thin longitudinal alar territory where Nkx2.1 signal is also found (arrowheads; Figures 5E-G; see also Bardet, 2007; Shimogori et al., 2010). It is unclear whether these few cells are newly arisen within CSPa, or correspond to an alignment of cells previously displaced from the CPa.
As regards the basal plate, Sst-positive cells at the $\mathrm{ABa}$ are more numerous at E13.5, compared to the E12.5 pattern. ABa Sstcells were found across the retrochiasmatic median plane, always accompanied by the more numerous Otp-positive ABa cells (not shown). We also found scattered Sst-positive cells extending toward the intrahypothalamic boundary (THy/PHy) along the entire ABa (Figures 5B,F,J). A few Sst neurons also seemed to have dispersed caudalward from the $\mathrm{ABa}$ into its retrotuberal (peduncular) counterpart, the posterobasal area (PBa; Figures 5F,G). Ventrally to the ABa, Sst-expressing cells - surrounded by Otp-positive cells - were also detected in the intermediate tuberal area, participating in the shell of the ventromedial hypothalamic nucleus (VMHs), stretched around its Sst-negative and Nkx2.1-positive core, particularly at its rostral aspect (VMHc; Figures $5 \mathrm{~A}-\mathrm{C}, \mathbf{E}-\mathbf{G}, \mathbf{M}-\mathbf{O})$. Fewer Sst/Otp cells were dispersed along the superficial tuberal stratum between the $\mathrm{ABa}$ and the superficial part of the arcuate nucleus (Arcs; Figures $5 \mathrm{M}-\mathbf{O}$ ). These zones apparently invaded by Otpand Sstcells produced at the ABa largely correlated topographically with Shh/Nkx2.1-positive domains (Figures 5E,G,H,O). 

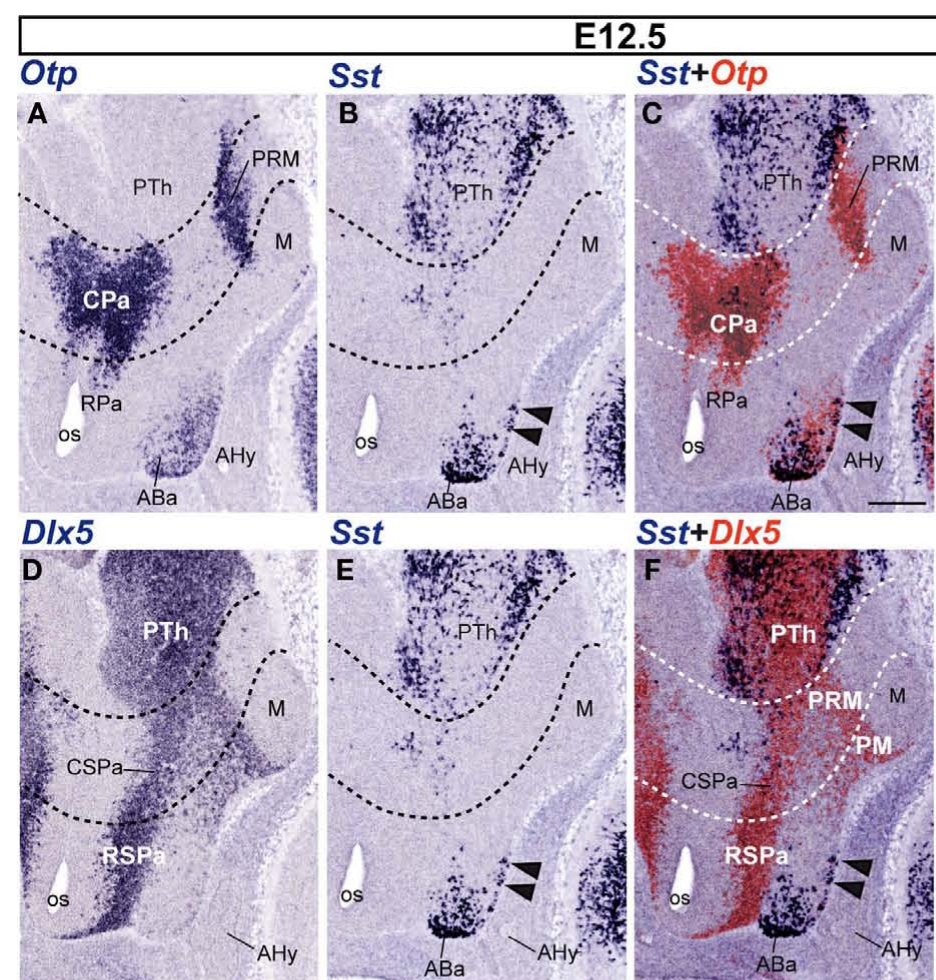

$S s t+D / \times 5$

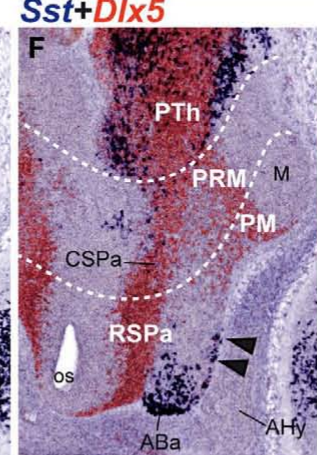

\section{$O t p+D / \times 5$}

Nkx2.1

\section{Sst}

\section{Sst+Nkx2.1}
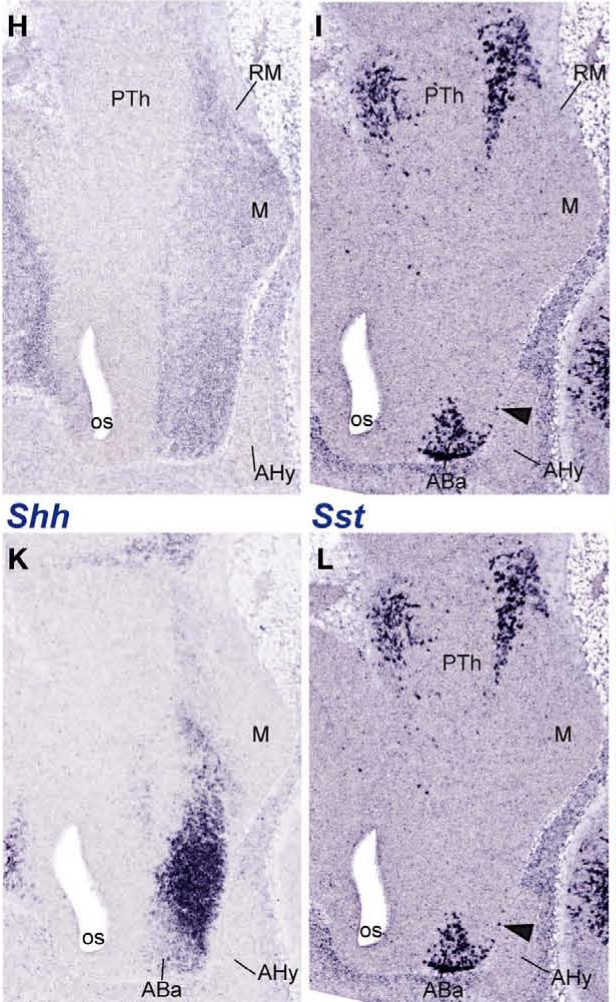

\section{Sst}
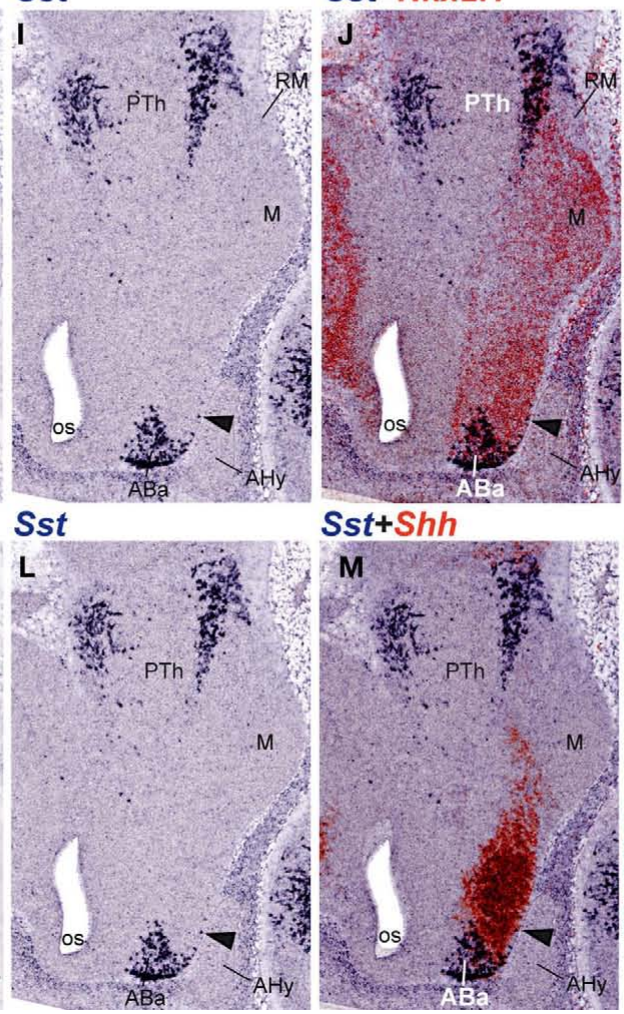

\section{Sst+Shh}

\section{Sst+Shh}
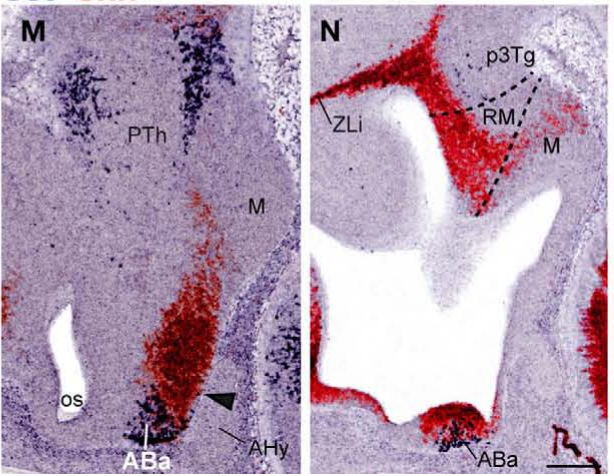

FIGURE 4 | Sagittal sections of E12.5 embryos taken at lateral (A-G) and medial $(\mathrm{H}-\mathrm{N})$ levels, correlating the indicated reference markers with the presence of Sst-positive cells. The transversal boundaries of the PHy and THy are indicated by dashed lines. Note there are abundant Sst cells within basal and alar regions of the prethalamus [PTh; p3Tg in $(\mathbf{N})$ ], which need to be

distinguished from the hypothalamic elements, found rostral to the hypothalamo-diencephalic boundary (caudal dashed line). The black arrowheads mark the incipient ventralward subpial displacement of some ABa-derived Sst cells. The white arrowheads in (G) indicate the sparse Otp-positive cells present within the CSPa subdomain. Bars $=200 \mu \mathrm{m}$. 

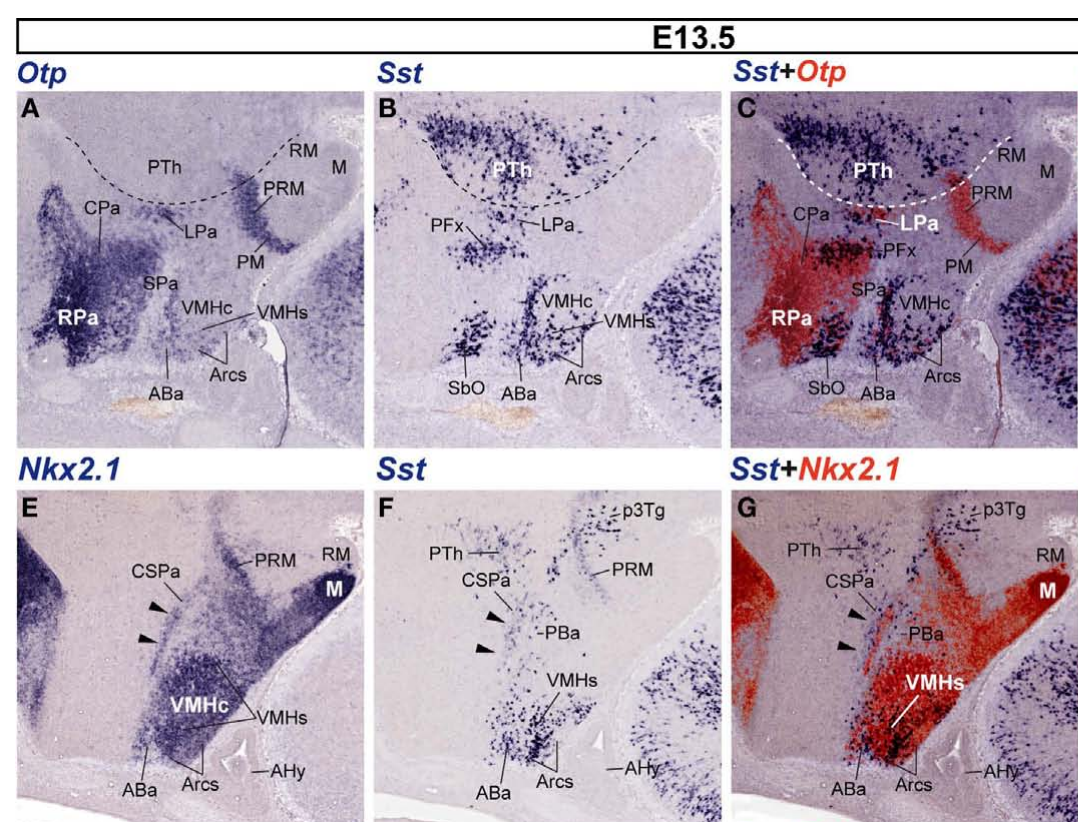

Sst+Dlx5
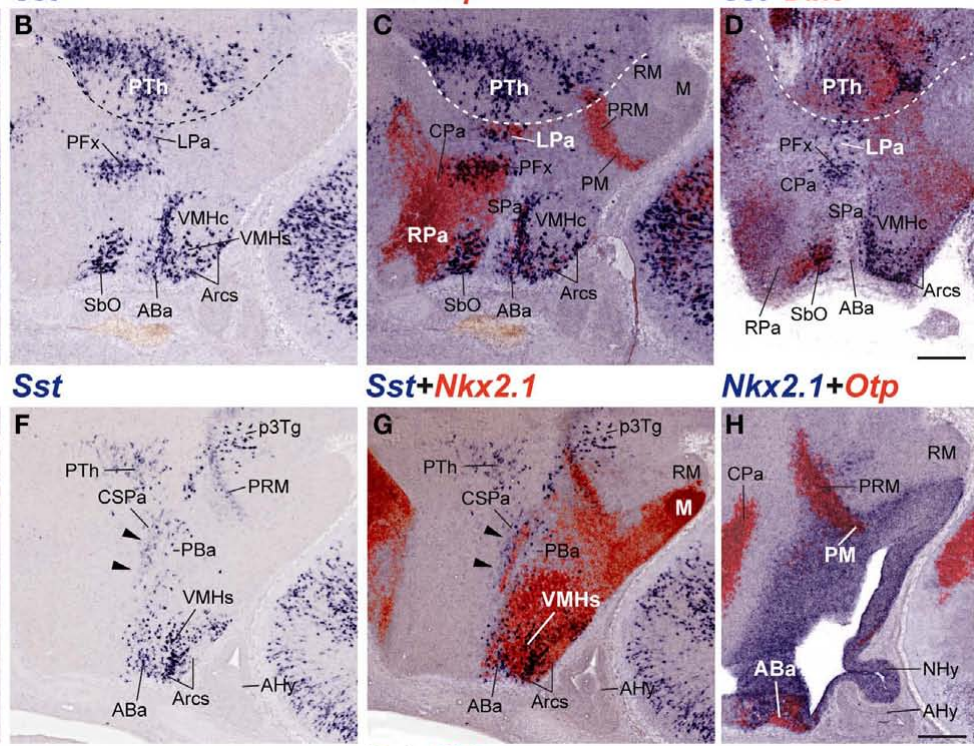

Shh

\section{Sst}

Sst+Shh
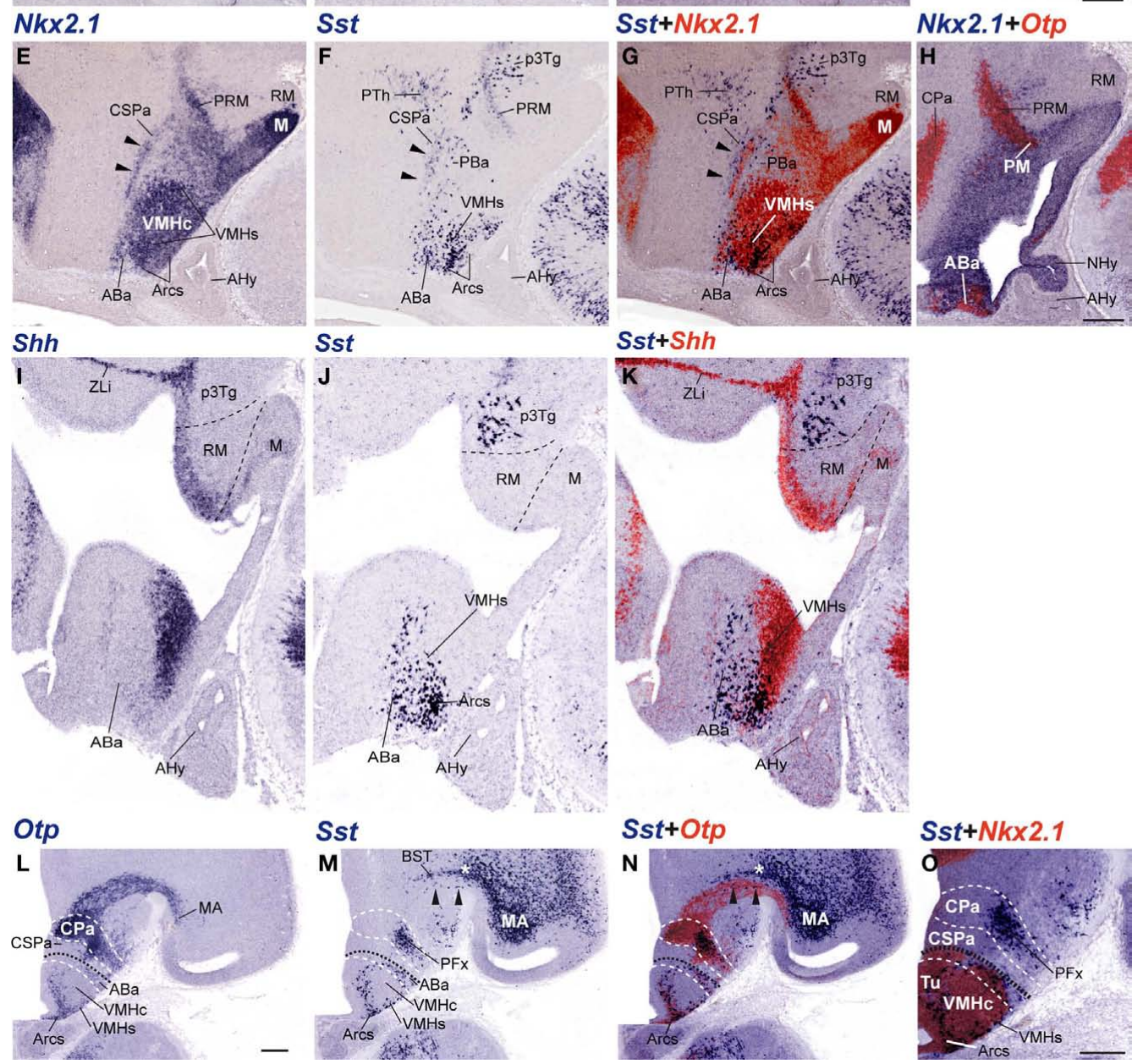

FIGURE 5 | Sagittal (A-K) and transversal (L-O) sections of E13.5 embryos taken at lateral (A-H) and medial (I-K) paramedian levels, correlating the indicated reference markers $(O t p, N k \times 2.1, D / \times 5)$ with the presence of Sst-positive cells. (A-G) these images reveal advanced migratory displacement of $\mathrm{ABa}$-derived Sst cells into the underlying $\mathrm{VMHs}$ and Arcs formations. (H)This nearly median section shows the ventricular domain expressing Nkx2.1, as well as its caudal extension along the PM/PRM band. The black arrowheads in (E-G) mark the area of overlap between Nkx2.1-expressing mantle cells and the sparse Sst-positive cell population found within the CSPa. Note also in $(\mathbf{F}, \mathbf{G})$ a few Sst-positive cells lying immediately ventral to the CSPa band, identified by us as the posterobasal nucleus (PBa), where Nkx2.1 signal is absent. This peculiar retrotuberal basal plate locus (compare Figure 1B) corresponds to an area selectively expressing $L h \times g$, recently described by Shimogori et al. (2010). (I-K) Dashed lines indicate the HDB and IHB limits demarcating the RM area from the prethalamic tegmentum (p3Tg) and the $\mathrm{M}$ area, next to the floor plate. (L-N) Correlation of Otp and Sst signals in adjacent transversal sections (orthogonal to the alar-basal boundary, marked by the black dashed line; white dashed lines indicate the main alar and basal subdivisions). The telencephalic Otp-positive migration stream of the CPa area - containing isolated Sst cells (black arrowheads in $\mathbf{M}, \mathbf{N}$ ) - enters the medial amygdalar area (MA), after passing underneath the Sst-positive elements of the subpallial bed nucleus striae terminalis complex (white asterisk; BST). The CPa area itself shows radial stratification of Otp-positive derivatives within its mantle layer (L,N). At intermediate levels of this domain, superficially migrated Sst cells form an aggregate interpreted as a perifornical population [PFX (MM,N)], though it may contain as well elements destined to reach the entopeduncular nucleus, more superficially (not shown). A higher magnification detail of this area is shown in (O). Within the basal plate, both Otp and Sst cells are observed at the VMHs and Arcs formations, as well as in the overlying $\mathrm{ABa}$. Corresponding overlap between Nkx2.1 and Sst signals is shown in (0). Bars $=200 \mu \mathrm{m}$. 
Moreover, we also detected at E13.5 a new group of Sstexpressing cells centered at the caudal end of the Otp-positive periretromamillary area, rostral to a pre-existent magnocellular Sst-positive prethalamic tegmental population (Figures 5C,E-G; compare Figures $\mathbf{5 H}-\mathbf{K}$ ). Interestingly, these $S$ st cells are restricted to the PRM within PHy and do not extend into the similarly Otppositive perimamillary band within THy. This periretromamillary Otp/Sst-positive hypothalamic domain overlaps topographically the perimamillary arch of $N k \times 2.1$ expression that extends into the prethalamic basal plate to end close to the zona limitans intrathalamica (PRM; ZLi; Figures 5E-H,I-K).

\section{Sst EXPRESSION PATTERN IN THE HYPOTHALAMUS AT E15.5}

The distribution of Sst mRNA was on the whole comparable to that obtained at E13.5, although with a larger number of Sst-expressing cells.

In the alar plate, the $\mathrm{Pa}$, still identified by dense Otp signal and absence of Dlx5 signal (Figures 6A,D,G), contains very few Sstexpressing cells at periventricular levels (medial hypothalamus; Figures 6B-F). Only sparse small Sst-positive cells appear within the $\mathrm{CPa}$ (Figures 6E,F). In contrast, there are two distinct Sstpositive cell aggregates - intermixed with Otp-positive cells - that appear displaced radially at caudal and rostral locations within the intermediate CPa level (lateral hypothalamus). These cell groups correspond to the lateral paraventricular nucleus (LPa), found just in front of the hypothalamo-prethalamic boundary, and a perifornical population, detected around the expected course of the fornix, close to the intrahypothalamic boundary; note that the fornix itself was not identified (PFx; LPa; Figure 6H). Superficially, the CPa displays as well Sst-positive cells at the entopeduncular nucleus, lying interstitial to the cerebral peduncle, dorsal to the level occupied by the subthalamic nucleus and slightly above the level where the optic tract courses longitudinally at the peduncular hypothalamic surface (Figure 6I). The underlying Dl $x 5$-positive CSPa still shows a sparse number of aligned Sst cells (Figures 6E,F). The RSPa, in contrast, is practically devoid of them.

Rostrally, close to the optic chiasma and lateral to the suprachiasmatic nucleus primordium, the RSPa appears invaded by a thick bridge of Otp-expressing cells that interconnects the overlying $\mathrm{RPa}$ - their apparent source, also containing the rounded Otppositive lateral anterior nucleus - with the underlying $\mathrm{ABa}$ areas (Figures 6D,F,H). Part of these cells possibly converge upon the supraoptic and/or suboptic nuclei. Deeper cells of this bridge may lie at this stage or later within the anterior hypothalamic nucleus (AH; Figures 6K,L). The mentioned bridge is however practically devoid of Sst cells at this stage (LA; AH; SO; Figures 6D-H). In more lateral sections, Sst-positive cells unmixed with Otp-positive cells appeared quite close to the Otp-positive supraoptic nucleus (SO), dorsal the optic tract, and extending into the suboptic nucleus (known as retrochiasmatic or accessory supraoptic nucleus) found under the optic tract (SbO; Figure 6I).

Abundant Sst-expressing cells were detected in the Dlx5-positive and NKX2.1-immunoreactive tuberal region of the hypothalamic basal plate, particularly within its terminal subdivision ( $\mathrm{ABa}, \mathrm{VMHs}$, Arcs; Figures 6C,L). The Sst cells always correlated topographically with Otp-expressing cell populations (Figures 6F,H,I). In contrast, few Sst cells were located within the core of the VMH nucleus, which was Dlx5 and Otp negative (VMHc; Figures 6A-F), but NKX2.1-immunoreactive (Figures 6J-L). We also found at E15.5 an increased number of Sst-expressing cells along the peduncular Otp-positive periretromamillary area, but not within its terminal continuation, the perimamillary area (PRM; PM; Figures 6B-H). Part of the PRM population has migrated radially to intermediate levels of the mantle zone (not shown).

\section{DISCUSSION}

This study represents the first to analyze in detail, by means of in situ hybridization, the spatiotemporal distribution of the earliest neuronal populations expressing the gene that encodes the SST hormone, in relation to the expression patterns of highly conserved homeobox genes such as Otp, Dlx5, Shh, and Nkx2.1, during ontogeny of the mouse hypothalamus. These reference transcription factors have been implicated in the regional patterning of hypothalamus (Shimamura and Rubenstein, 1997; Bertrand and Dahmane, 2006; Yee et al., 2009; Shimogori et al., 2010) and/or the specification of distinct neuroendocrine hypothalamic cells (Acampora et al., 1999; Michaud, 2001; Caqueret et al., 2005; Blechman et al., 2007).

The most relevant results of our study can be summarized as follows: (1) Sst-positive cells were first discernible in the basal ABa nucleus at E10.5; (2) as development progressed, Sst expression increased particularly within terminal basal hypothalamic areas, apparently extending from the precocious $\mathrm{ABa}$ into the subjacent VMHs and Arcs territories; these cells lie within the Nkx2.1-positive territory; (3) Sst-positive cell populations also developed separately within the alar Dlx5-negative and Otp-positive CPa and RPa areas, particularly at the ventral part of the paraventricular complex (giving rise caudally mainly to radially migrated lateral paraventricular, perifornical and entopeduncular Sst-positive derivatives, and rostrally to the superficially migrated primordium of the suboptic nucleus, also known as retrochiasmatic supraoptic nucleus); an apparent dispersion or migration of alar cells into the subjacent Dlx5-positive SPa area was observed as well; (4) a fourth group of Sst-expressing cells appeared in the peduncular Otp-positive periretromamillary domain; (5) Sst-expressing cells generally correlated topographically with more abundant Otp-expressing cells, either inside or outside the primarily Otp-positive progenitor domains, though there are extensive $\mathrm{Pa}$ regions where Otp signal is not accompanied by Sst signal; and (6) Sst cells appearing secondarily at the SPa, VMHs and Arcs domains may represent migratory events.

A remarkable negative observation is that some important Sstexpressing cell populations described in the adult mouse brain (e.g., see Allen Developing Mouse Brain Atlas ${ }^{4}$ ) are not present in our material up to E15.5. The main cell groups missing are those at the anterior periventricular nucleus and the ventral paraventricular nucleus (conventionally identified as "posterior paraventricular nucleus"). Data at the Allen atlas suggest that they differentiate after E18.5, and the full population can be seen at around P28. This heterochronic differentiation pattern does not alter our analysis of early embryonic stages. Our discussion therefore focuses on points 5 and 6 above. First, we examine the progenitor domains where early hypothalamic Sst-cells are produced, and, discuss whether

${ }^{4}$ http://www.developingmouse.brain-map.org/ 


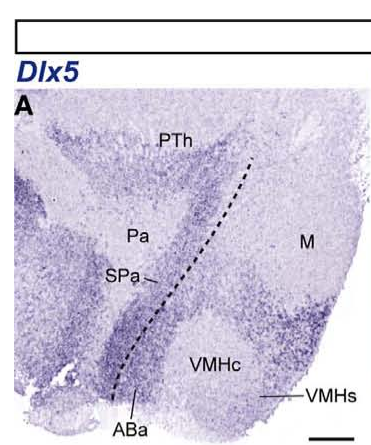

Otp

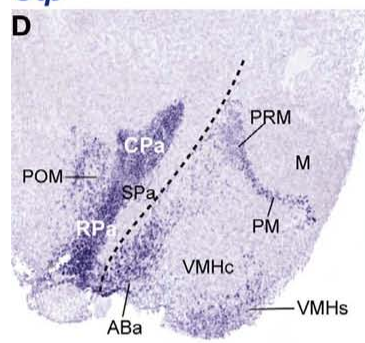

$O t p+D \mid \times 5$

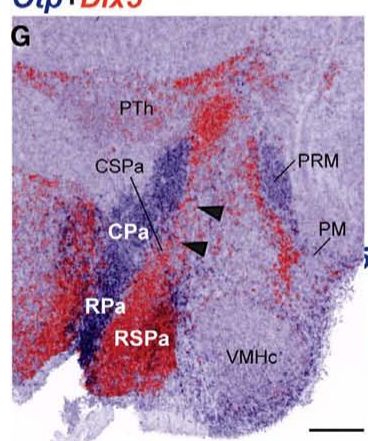

NKX2.1

$\mathrm{J}$

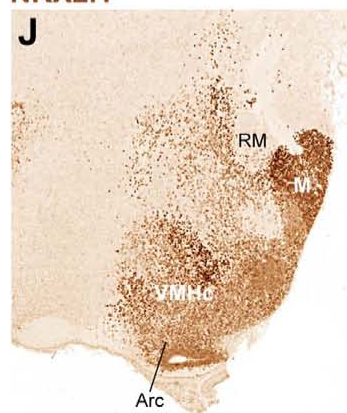

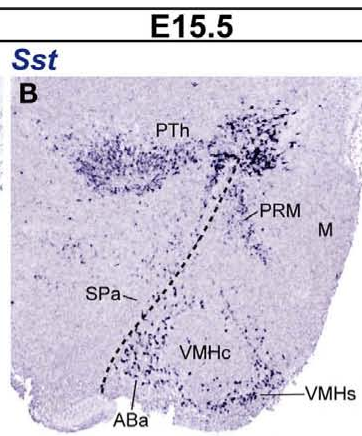

Sst

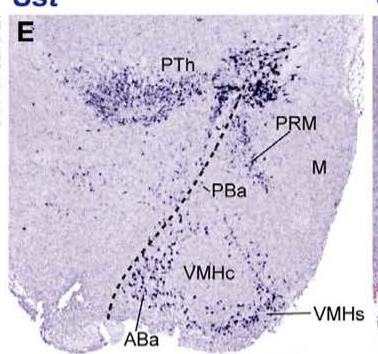

Sst+Otp

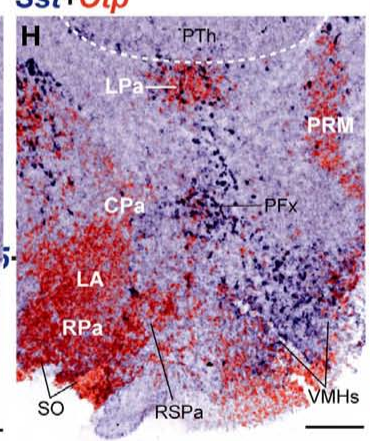

Sst

K

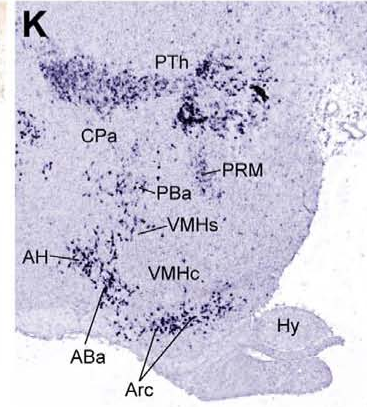

Sst+DIx5

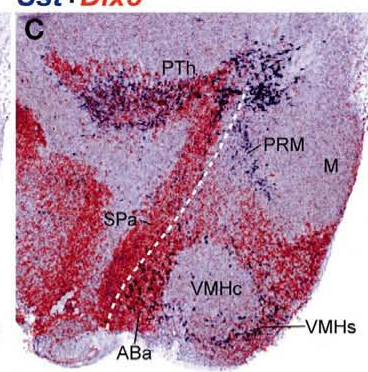

Sst+Otp

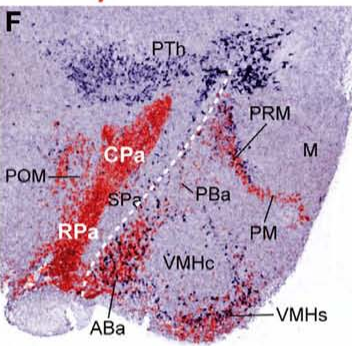

Sst+Otp

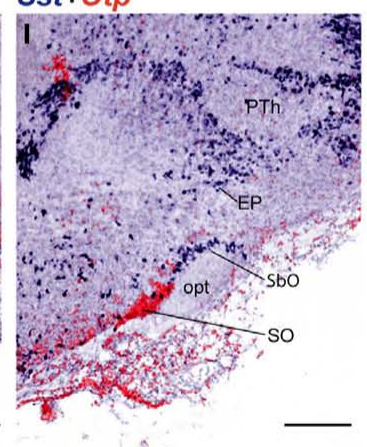

NKX2.1+Sst

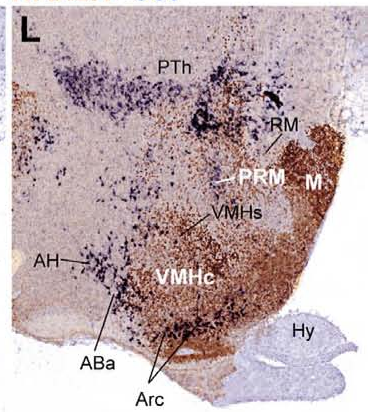

FIGURE 6 | Sagittal sections of E15.5 embryos, correlating the indicated reference markers with the presence of Sst-positive cells in adjacent sections. (A-I) This series of sections is a medio-lateral progression, where (A-F) represent adjacent sections compared to each other by digital overlap $(\mathbf{C}, \mathbf{F})$, and the analogous overlaps shown in (G-I) lie progressively more laterally. The dashed lines in (A-F) indicate the alar-basal boundary. Note non-hypothalamic D/x5 and Sst expression in the prethalamus (PTh), but restriction of Otp to hypothalamus. The VMHs and Arcs formations express $D / \times 5$, whereas the $\mathrm{VMHc}$ does not (C). Note as well close neighborhood of D/x5 signal to Otp signal at the Pa and PRM domains (G). (J-L) Sagittal adjacent sections from a different E15.5 embryo, correlating NKX2.1 immunoreaction with the distribution of Sst cells. Bars $=200 \mu \mathrm{m}$. there is a shared molecular background that represents a causal common denominator for this neuronal phenotype. This question is relevant because Sst cells appear to be distributed widely in the adult hypothalamus. Various recent lines of evidence in other parts of the brain suggest that chemically characterized neuron types usually are produced in specific progenitor domains and may disperse migratorily more or less as they incorporate in the mantle zone and differentiate. This leads to a second issue, whether some Sst cell groups migrate from their primary origins into other parts of the hypothalamus. 


\section{Sst SOURCE AREAS AND THEIR MOLECULAR BACKGROUND}

As regards characterizing the early sources of Sst cells, we used comparative mapping in adjacent cryostat sections of gene markers - Shh, Nkx2.1, Dlx5, Otp - known to divide the hypothalamic wall into a number of distinct neurogenetic domains. In this way we could distinguish the alar-basal boundary, indicated by the interface of the basal markers Shh and Nkx2.1 with the alar marker $D l x 5$ (irrespective of the latter also appears later in part of the basal plate). Moreover, Otp and Dlx5 respectively distinguish the paraventricular and subparaventricular areas within the alar plate, and Dlx5 becomes secondarily expressed in the tuberal region of the basal hypothalamus, stopping at its longitudinal border with the mamillary body. The latter shows intercalated between this border and the mamillary and retromamillary nuclear complex the Otp-positive perimamillary/periretromamillary band. Since we also divide the whole hypothalamus into terminal (THy) and peduncular (PHy) anteroposterior parts (Figure 1A; see Allen Developing Mouse Brain Atlas), consistently with gene mappings summarized in the Section "Introduction," the diverse dorsoventral molecular patterns establish a framework of 12 histogenetic areas (Figure 1C), where the Sst cells can originate and eventually mature. Our data for E10.5-E15.5 embryonic stages clearly pinpointed at least four independent sources for the studied cell type. These correspond to the $\mathrm{ABa}$ (a rostrodorsal basal tuberal area), the CPa (a peduncular dorsal alar domain), the RPa (a terminal dorsal alar domain), and the periretromamillary (PRM) domain (a caudal component of the mamillary body; Figure 7). A minor cell group observed within the CSPa may represent yet another potential independent contingent, though its non-migratory character is still uncertain. This listing does not pre-empt the possibility that additional progenitor sources may turn out to be relevant in the present context, but show a retarded upregulation of the Sst gene in their derivatives, which accordingly only become identifiable perinatally.

The molecular background associated to the four main Sst cell sources is variable, as one would expect from the wide anteroposterior and dorsoventral range of the respective topographies across our frame of reference (Figures 1C and 7). Nevertheless, this background shows shared aspects that may guide causal analysis of the specification cascade leading to the Sst neuronal phenotype. In the first place, there is a clearcut common relationship of emergent Sstcells to a surrounding and pre-existent Otp-positive cell population. Even migrating Sstcells have surrounding, similarly migrating Otp-positive cells. Since in several cases the incipient populations observed by us up to E15.5 increase spectacularly perinatally, it is possible to conceive that the Sst phenotype differentiates gradually within a pre-existent population labeled by the Otp signal.

Secondly, mere expression of Otp is not sufficient to condition upregulation of the Sst gene, since the large $\mathrm{Pa}$ area is full of Otp-positive cells from very early stages of development, and only few Sst differentiate there between E10.5 and E15.5. Interestingly, these few Pa-derived Sst cells are associated to the ventral-most part of both the CPa and RPa, which suggests a relationship with a specific added local causal effect, possibly the expression of Sim2, whose deletion causes disappearance of Sst and Trh cells at the paraventricular nucleus complex (Goshu et al., 2004). Similarly, the Otp-positive periretromamillary/perimamillary band develops Sst cells between E13.5 and E15.5, but only within its caudal periretromamillary portion (PRM). Sim1/2 genes are also expressed in this area (Allen Atlas; Shimogori et al., 2010, supplementary data). In both $\mathrm{Pa}(\mathrm{CPa}+\mathrm{RPa})$ and PRM, the Otp-positive area lies adjacent to Dlx5-expressing, Otp/Sst-negative domains ( $\mathrm{SPa}$ in the case of the ventral $\mathrm{Pa}$, and tuberal/retrotuberal area in the case of the PRM). The Arx gene also appears expressed at the SPa, just under the ventral $\mathrm{Pa}$ subdomain, and in a tuberal band adjacent to the PRM, superposed to Dlx5 (Shimogori et al., 2010).

As regards the terminal $\mathrm{ABa}$ domain, Sst cells also correlate there with pre-existing numerous Otp cells, and there is a neighboring Dlx5/Arx-expressing domain, the RSPa. Moreover, its cells express $N k x 2.1$, as happens likewise at the PRM, but not at the Pa domains. The few Sst cells that differentiate early on at the ventral CSPa also coincide both with Otp-positive cells, a $D l \times 5$-positive environment and the expression of $N k x 2.1$ (Bardet, 2007; Shimogori et al., 2010). On the other hand, the PBa domain lying caudal to ABa (displaying similar molecular neighborhood relationships as the $\mathrm{ABa}$, but lying at the PHy) produces few Sst cells between E10.5 and E15.5, a

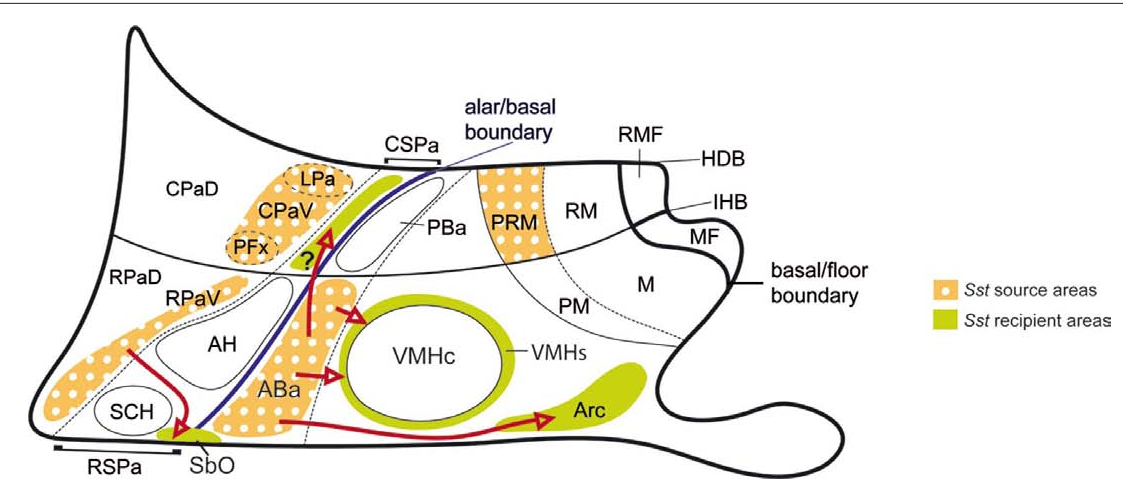

FIGURE 7 | Schematic color-coded mapping (upon our basic schema of Figures 1B,C) of the described Sst source areas and the apparent Sst recipient areas, involving postulated tangential migrations (red arrows). The migration moving cells potentially from the ABa to the CSPa is marked with an interrogant because the intrinsic versus extrinsic origin of these cells is not clearly distinguishable in our material. Note that we described radial migrations toward intermediate or subpial loci at the ventral subdomains of $\mathrm{CPa}$ and $\mathrm{RPa}(\mathrm{CPaV}, \mathrm{RPaV})$ and $\mathrm{PRM}$ areas. Only the radial migration finishing at the suboptic nucleus (SbO; or retrochiasmatic supraoptic nucleus) is represented. 
difference in pattern that is not readily understood. Nevertheless the PBa generates many Sst cells at later perinatal stages (Allen Atlas). This may be related to the fact that the $\mathrm{PBa}$ area coincides with a restricted longitudinal basal domain of the dorsal retrotuberal region where $N k x 2.1$ is singularly not expressed (see Figure 5F); another peculiar molecular characteristic of this area is its expression of the $L h x 9$ gene (Shimogori et al., 2010). It can be conjectured that this distinct molecular code may underlie, at least in part, the observed retarded differentiation pattern.

As is discussed below, we associate the ABa source of Sst cells to the subsequent appearance of this sort of neurons at the VMHs and the Arcs domains, presumably due to ventralward tangential migration. We discuss here these populations in the genetic background context. The molecular background conditions discussed above for the primary sources of Sst cells do not seem to apply at the VMHs or Arcs. The only connection seems to be the progressive invasion of Otp/Sst-positive cells into these differentiating tuberal areas. Interestingly, it has been shown that mice lacking Otp function lose the STT-producing or Sst-expressing cells both at the Arc and "an adjacent area” (probably the VMHs; Acampora et al., 1999; Wang and Lufkin, 2000). Moreover, Nkx2.1, a well-known gene expressed early on through most of the basal hypothalamus (Shimamura et al., 1995; Shimamura and Rubenstein, 1997), is likewise required for the development of basal tuberal hypothalamic areas such as the Arc and VMH (Kimura et al., 1996). In addition, Shh is expressed even earlier in the notochord and the prechordal plate underlying the forebrain. The peptidic SHH morphogen coded by Shh is a diffusible signal that eventually induces its own expression in the hypothalamic floor and basal plate cells, as well as the expression of other genes, such as Nkx2.1 (Erickson et al., 1995; Dale et al., 1997; Pera and Kessel, 1997; Shimamura and Rubenstein, 1997; Pabst et al., 2000). Considering these data, we postulate that Shh, $N k x 2.1$, and Otp are part of the genetic network involved in the early specification of the precocious Sst-expressing cells at their ABa source. However, basal expression of Shh, Nkx2.1, and Dlx5 in the tuberal area may influence the guidance of Sst cells into the VMH and Arc territories, as well as their definitive stabilization therein. Restriction of the ABa Sst pattern to the peduncular part of the hypothalamus may be related to the general presence of the Six 3 gene at the rostral midline, which is needed to activate Shh at this locus (Geng et al., 2008), as well as to the restricted local activity of the Neurog3 gene (Allen atlas). Curiously, the ABa seemed not be affected in Nkx2.1 knockout mice, though the Arc and VMH did not develop, or were abnormal, respectively (Kimura et al., 1996). It will be of interest to analyze Sst ontogeny in these knockout mice.

\section{CHARACTERIZATION OF Sst DIFFERENTIATION AT THE ABa}

The ABa progenitor domain had not been related to Sstcell production before. Sst-positive cells were first identified in our material as early as E10.5 at the ABa, which is known as one of the most precociously differentiating forebrain populations (Shimada and Nakamura, 1973). Other developmental reports on hypothalamic Sst cells were apparently less sensitive. In E14 mouse embryos, Bendotti et al. (1990) exclusively reported Sst mRNA expression in the entopeduncular nucleus. This observation may correspond to Sst-positive cells observed at E13.5 at the intermediate radial level of $\mathrm{CPa}$, some of which subsequently apparently migrate radially into the EP nucleus. SST-immunoreactive cells in the entopeduncular nucleus were detected at E17 in the rat embryo study of Shiosaka et al. (1982). At this stage, these authors also located early SSTpositive cells in a region near the root of the mamillothalamic tract; these probably correspond to our Sst-expressing cells at the peduncular periretromamillary band, observed from E13.5 onward in the mouse. Surprisingly, the precocious ABa population was not detected in this study. In the mouse, cells at the corresponding location were first distinguished after birth by immunohistochemistry (Forloni et al., 1990) or in situ hybridization (Bendotti et al., 1990), while SST-immunoreactive cells were detected at fetal day 19 in the rat (Shiosaka et al., 1982). A secondary perinatal surge of detectable SST is likely related to the functional role of SST in inhibiting the release of growth hormone from the anterior pituitary (Gross and Longer, 1979).

The ABa seems to be a particular area of the basal plate, which forms an U-shaped neuronal formation (there is a median portion and two lateral, caudally oriented wings of the ABa), which is restricted in extent to the terminal part of the basal hypothalamus, just under the alar-basal boundary and dorsal to the VMH nucleus. Data offered at the Allen Developing Mouse Brain Atlas reveal that the proneurogenic Neurog3 gene is expressed selectively at the terminal ABa locus at E11.5. Moreover, the Otp data at the Allen Atlas for this stage corroborate our finding of a precocious Otp-positive $\mathrm{ABa}$ population, born strictly separately from that appearing at the peduncular and terminal paraventricular subareas. As mentioned above, the $\mathrm{ABa}$ was already known as one of the most precociously differentiated forebrain areas (Altman and Bayer, 1978, 1986, 1995) and is comparable to the avian retrochiasmatic nucleus of Puelles et al. (1987). According to our results, the sizeable Otp-positive cell population of this primordium also expresses $N k \times 2.1$ and $S h h$ from E10 to E15.5. This strongly supports a basal plate origin. The early Sst cells appear as a smaller population intermixed with these Otp cells. They accordingly also seem to have a rostral basal origin restricted to the terminal $\mathrm{ABa}$ area (rostral-dorsal tuberal area). While numerous Otp cells clearly do not express Sst (within the sensibility of our ISH protocol), our material does not allow to assess whether all or some Sst cells also express Otp. Interestingly, Shh expression seems to become downregulated at the ABa mantle zone in parallel to the increase in the number of local Otp/Sst-positive cells. Presence of STT-immunoreactive cells at the retrochiasmatic area $(\mathrm{ABa})$, as well as surrounding the $\mathrm{VMH}$, has been described in adult mammals (Hoffman and Hayes, 1979; Johansson et al., 1984; Scanlan et al., 2003) and in the developing hypothalamus of the rat (Shiosaka et al., 1981).

\section{POSSIBLE MIGRATION OF SOME Sst CELL POPULATIONS}

The Sst cell population formed at the ABa is always paralleled by a Otp population, and remarkably involves up to E15.5 a ventralward dispersion of part of both populations. Cells spreading ventrally from the arms of the $\mathrm{ABa}$ surround the glutamatergic $\mathrm{VMH}$ core nucleus and colonize its shell domain (VMHs; Figure 7). Other cells imitate this behavior at the median and paramedian regions of the $\mathrm{ABa}$ and penetrate the underlying tuberal region, ingressing centrally into the peripheric shell of the Arc nucleus (Arcs) and more laterally into bilateral wing-shaped subpial domains associated to the Arcs (Arcs; Figure 7). The tuberal arcuate nucleus is a 
heterogeneous nucleus characterized in the adult by diverse neuroendocrine cell types (Dierickx and Vandesande, 1979; Johansson et al., 1984; Lechan and Fekete, 2006). Various chemoarchitectonic mappings of its components suggest an organization into core and shell domains (Arcc; Arcs; Fuxe et al., 1985; Zoli et al., 1986). Though losing in this way a part of its population, the ABa itself remains well populated, at least up to E15.5. Expression data for Sst at the Allen Atlas suggest that the ABa population diminishes at later stages, a pattern indicating that perhaps most of its elements finally translocate ventralward. The conjecture that we deal here with a tangential migratory process is based on the temporal sequence of observations, the relative density of Sst cells at the cited locations at different stages and the unlikeness of the possibility that this phenomenon can be explained by a radial migration. In particular, the population of Sst cells at the Arc nucleus is non-existent before the Otp/Sst-positive cells translocating from the ABa reach it. At subsequent stages, the number of these Arc cells increases spectacularly, possibly also due to retarded differentiation of early Otp-positive/Sst-negative elements into Sst neurons. It should be noted that another cell population is known to first develop at the $\mathrm{ABa}$, and then becomes displaced ventralward into the Arcs and VMHs. We refer to proopiomelanocortin neurons found later at the adult Arc (Shimogori et al., 2010; look up Pomc in the Allen Developing Mouse Brain Atlas). It remains to be studied whether there is any causal relationship between these two neuropeptidergic cell types with a parallel developmental pattern.

Tangential migration of SST cells has been reported in other areas of the brain, such as in the case of SST cells originated from the basal telencephalon that contribute via tangential migration to Sst-positive GABAergic interneurons of the striatum and cerebral cortex (Anderson et al., 2001; Nery et al., 2002). Tangential migration recently is appearing not to be exceptional, as it occurs either strictly inside the developing hypothalamus (Alvarez-Bolado et al., 2000) or transferring cells from nearby or remote regions outside the hypothalamus into it (Schwanzel-Fukuda and Pfaff, 1989; Wray et al., 1989; Zhao et al., 2008). Cell populations migrating from the diencephalon - the prethalamus - into the hypothalamus were recently identified by genetic labeling of the Foxb1 cell lineage (Zhao et al., 2008). According to the published images, a prethalamic Foxb1 migratory stream contributes to the preoptic area and alar hypothalamic domains (their "anterior portion of the lateral hypothalamic area").

Sparse Sst-positive cells were detected from the earliest stages examined, though more prominently from E13.5 onward, in a ventral portion of the alar Dlx5-expressing RSPa domain, mixed with sparse Otp-expressing cells. Theoretically, these cells may have been produced locally in the SPa domain, or may have migrated from elsewhere. The molecular background of the SPa is quite different from that of the $\mathrm{Pa}$, since its derivatives basically express $\mathrm{Dl} x 5$ and Arx; DLX function conditions differentiation into GABAergic neurons (Stühmer et al., 2002). In contrast, the Pa derivatives largely differentiate as neurohormonal neuronal types of various sorts, none of which seems to be GABAergic. On the other hand, the $\mathrm{ABa}$ population expresses distinctively the basal marker $N k \times 2.1$, not present in general in the $\mathrm{Pa}$ or SPa, and the CSPa population of Sst-expressing cells coincides topographically with a line of $N k \times 2.1$ positive cells (Bardet, 2007; Shimogori et al., 2010). This might support a tangential migration from the underlying $\mathrm{ABa}$ (CSPa; Figure 7), but present evidence does not allow discarding the possibilities of a locally generated character of this Sstpopulation at the $\mathrm{SPa}$, or a tangential migration from the $\mathrm{CPa}$. In contrast, the $\mathrm{RPa}$ seems to generate the sizeable rostral migratory Otp/Sst-positive population that bypasses laterally the suprachiasmatic nucleus as it traverses dorsoventrally the RSPa to reach finally the suboptic surface, transforming into the suboptic Sst cells (SbO; Figure 7). This would imply a sequence of tangential plus radial migration.

Apart of the instances where tangential migration seems to happen, we also noted examples of significant radial migration of Sst cells. This occurs particularly at the $\mathrm{CPa}$ area, where results at E13.5 and E15.5 indicated radial translocation of Sst cells into intermediate levels of the corresponding part of the lateral hypothalamus. These intermediate cells aggregate either at the lateral paraventricular nucleus or at a specific perifornical population. Since the fornix tract courses dorsoventrally across the entire PHy, adjacent to the intrahypothalamic boundary, it is associated not to a single perifornical nucleus, as suggested in the conventional structural schema of the hypothalamus, but to a series of perifornical populations belonging to the diverse molecular domains (Figures 1B,C). The Sst-positive one is therefore just one component of the whole perifornical complex. We also detected that Sst cells developing at the same progenitor area $(\mathrm{CPa})$ reach superficially an entopeduncular position, which implies a longer range of radial migration. While the ABa-generated Sst cells do not seem to migrate radially at all, some of the Sst cells formed at the RPM do migrate radially, but do not reach the brain surface, and seem to stop deep to the cerebral peduncular tract, caudal to the subthalamic nucleus.

In conclusion, our data show novel aspects such as the detection of the first Sst-positive cells at the ABa, a population apparently distributing Sst cells to neighboring basal populations, followed by analogous cells developing separately within a ventral subdomain of the $\mathrm{Pa}$ area $(\mathrm{RPaV}, \mathrm{CPaV})$ and at the subjacent CSPa alar domain, or, separately, at the basal periretromamillary area. All these sources are characterized by the expression of the OTP transcription factor, and the absence of $D l x 5$ expression. The alar versus basal sources seem to be distinguished by the presence of $N k \times 2.1$ as a widespread basal marker, though this is also associated to the small contingent of Sst cells developing at the SPa. Various radially migrated Sst cell groups were described. Moreover, our results suggest the existence of diverse Sst-expressing cell populations that migrate tangentially within the hypothalamus, contributing to its structural and genoarchitectonic complexity. Our conjectures in this regard predict observations that may be checked experimentally, using Sst mouse lines to trail the Sst cell lineage in combination with specific developmental and neuronal and/or glial markers. The temporal distribution of Sst expression observed is more complex than previously reported, particularly at the basal hypothalamus. Analysis of the final distribution of Sst cells will require a correlation of present results with perinatal developmental stages, since several well-known adult components are not yet differentiated at E15.5.

\section{ACKNOWLEDGMENTS}

This work was funded by the Local Government of Castilla-La Mancha grant PII1I09-0065-8194 ( Carmen Díaz), the Spanish Ministry of Science and Innovation grant BFU2008-04156 
and SENECA Foundation contract 04548/GERM/06-10891 (Luis Puelles). Nicanor Morales-Delgado is a Ph.D. student at Castilla-La Mancha University under contract from the BFU200804156 grant, and Paloma Merchan is a postdoctoral fellow of NIH

\section{REFERENCES}

Acampora, D., Postiglione, M. P., Avantaggiato, V., Di Bonito, M., and Simeone, A. (2000). The role of Otx and Otp genes in brain development. Int. J. Dev. Biol. 44, 669-677.

Acampora, D., Postiglione, M. P., Avantaggiato, V., Di Bonito, M., Vaccarino, F. M., Michaud, J., and Simeone A. (1999). Progressive impairment of developing neuroendocrine cell lineages in the hypothalamus of mice lacking the Orthopedia gene. Genes Dev. 13, 2787-2800.

Altman, J., and Bayer, S. A. (1978). Development of the diencephalon in the rat. I. Autoradiographic study of the time of origin and settling patterns of neurons of the hypothalamus. $J$. Comp. Neurol. 182, 945-971.

Altman, J., and Bayer, S. A. (1986). The development of the rat hypothalamus. Adv. Anat. Embryol. Cell Biol. 100, 1-178.

Altman, J., and Bayer, S.A. (1995). Atlas of Prenatal Rat Brain Development. Boca Raton: CRC Press.

Alvarez-Bolado, G., Zhou, X., Cecconi, F., and Gruss, P. (2000). Expression of Foxb1 reveals two strategies for the formation of nuclei in the developing ventral diencephalon. Dev. Neurosci. 22, 197-206.

Anderson, S. A., Marín, O., Horn, C., Jennings, K., and Rubenstein, J. L. (2001). Distinct cortical migrations from the medial and lateral ganglionic eminences. Development 128 , 353-363.

Bardet, S. M. (2007). Organización morfológica y citogenética del hipotálamo del pollo sobre base de mapas moleculares. Doctoral thesis, Neuroscience Programme, University of Murcia, Spain.

Bardet, S. M., Cobos, I., Puelles, E., Martínez de-la-Torre, M., and Puelles, L. (2006). The chicken lateral septal organ and other circumventricular organs form in the striatal domain, abutting the molecular striatopallidal border. J. Comp. Neurol. 499, 745-767.

Bardet, S. M., Martinez-de-la-Torre, M., Northcutt, R. G., Rubenstein, J. L., and Puelles, L. (2008). Conserved pattern of OTP-positive cells in the paraventricular nucleus and other hypothalamic sites of tetrapods. Brain Res. Bull. 75, 231-235.

Bendotti, C., Hohmann, C., Forloni, G., Reeves, R., Coyle, J. T., and
Oster-Granite, M. L. (1990). Developmental expression of somatostatin in mouse brain. II. In situ hybridization. Brain Res. Dev. Brain Res. 53, 26-39.

Bertrand, N., and Dahmane, N. (2006). Sonic hedgehog signaling in forebrain development and its interactions with pathways that modify its effects. Trends Cell Biol. 16, 597-605.

Blechman, J., Borodovsky, N., Eisenberg, M., Nabel-Rosen, H., Grimm, J., and Levkowitz, G. (2007). Specification of hypothalamic neurons by dual regulation of the homeodomain protein Orthopedia. Development 134 4417-4426.

Brazeau, P., Vale, W., Burgus, R., Ling, N., Butcher, M., Rivier, J., and Guillemin, R. (1973). Hypothalamic polypeptide that inhibits the secretion of immunoreactive pituitary growth hormone. Science 179, 77-79.

Bulfone, A., Puelles, L., Porteus, M. H., Frohman, M. A., Martin, G. R., and Rubenstein, J. L. (1993). Spatially restricted expression of Dlx-1, Dlx-2 (Tes-1), Gbx-2, and Wnt-3 in the embryonic day 12.5 mouse forebrain defines potential transverse and longitudinal segmental boundaries. $J$. Neurosci. 13, 3155-3172.

Caqueret,A., Yang, C., Duplan, S., Boucher, F., and Michaud, J. L. (2005). Looking for trouble: a search for developmental defects of the hypothalamus. Horm. Res. 64, 222-230.

Cobos, I., Shimamura, K., Rubenstein, J. L., Martinez, S., and Puelles, L. (2001). Fate map of the avian anterior forebrain at the four-somite stage, based on the analysis of quail-chick chimeras. Dev. Biol. 239, 46-67.

Cotter, J. R., and Laemle, L. K. (1987). Distribution of somatostatinlike immunoreactivity in the brain of the little brown bat (Myotis lucifugus). Am. J. Anat. 180, 280-294.

Dale, J. K., Vesque, C., Lints, T. J., Sampath, T. K., Furley, A., Dodd, J., and Placzek, M. (1997). Cooperation of BMP7 and $\mathrm{SHH}$ in the induction of forebrain ventral midline cells by prechordal mesoderm. Cell 90, 257-269

Dierickx, K., and Vandesande, F. (1979). Immunocytochemical localization of somatostatin-containing neurons in the rat hypothalamus. Cell Tissue Res. 201, 349-359.

Ericson, J., Muhr, J., Jessell, T. M., and Edlund, T. (1995). Sonic hedgehog: a common signal for ventral patterning

grant 1-R01-MH070370-01A2 ( Luis Puelles). Infrastructural support provided by the Centre for Biomedical Research and Institute for Research in Neurological Disabilities (Castilla-La Mancha) is acknowledged.

along the rostrocaudal axis of the neural tube. Int. J. Dev. Biol. 39, 809-816. Fan, C.-M., Kuwana, E., Bulfone, A. Fletcher, C. F., Copeland, N., Jenkins, A., Crews, S., Martinez, S., Puelles, L., Rubenstein, J. L. R., and TessierLavigne, M. (1996). Expression patterns of two murine homologs of Drosophila single-minded suggest possible roles in embryonic patterning and in the pathogenesis of Down syndrome. Mol. Cell. Neurosci. 7, 1-16. Flames, N., Pla, R., Gelman, D. M. Rubenstein, J. L. R., Puelles, L., and Marín, O. (2007). Delineation of multiple subpallial progenitor domains by the combinatorial expression of transcriptional codes. J. Neurosci. 27 , 9682-9695.

Forloni, G., Hohmann, C., and Coyle, J. T. (1990). Developmental expression of somatostatin in mouse brain. I. Immunocytochemical studies. Brain Res. Dev. Brain Res. 53, 6-25.

Fuxe, K., Agnati, L. F., Kalia, M., Goldstein, M., Andersson, K., and Härfstrand, A (1985). “The dopaminergic systems in the brain and in the pituitary," in Basic and Clinical Aspects of Neuroscience, eds E. Fluckiger, E. Muller, and M. Thorner (Amsterdam: Springer Press), 11-25.

García-Moreno, F., Pedraza, M., Di Giovannantonio, L. G., Di Salvio, M. López-Mascaraque, L., Simeone, A. and De Carlos, J. A. (2010). A neuronal migratory pathway crossing from diencephalon to telencephalon populates amygdala nuclei. Nat. Neurosci. 13, 680-689.

Geng, X., Speirs C., Lagutin O., Inbal A., Liu W., Solnica-Krezel L., Jeong Y., Epstein D., and Oliver G. (2008). Haploinsufficiency of Six 3 fails to activate Sonic hedgehog expression in the ventral forebrain and causes holoprosencephaly. Dev. Cell 15, 236-247.

Goshu E., Jin H., Lovejoy J., Marion J.-F., Michaud J. L., and Fan C. -M. (2004). $\operatorname{Sim} 2$ contributes to neuroendocrine hormone gene expression in the anterior hypothalamus. Mol. Endocrinol $18,1251-1262$.

Gross, D. S., and Longer, J. D. (1979) Developmental correlation between hypothalamic somatostatin and hypophysial growth hormone. Cell Tissue Res. 202, 251-261.

Hallonet, M., Hollemann, T., Wehr, R., Jenkins, N. A., Copeland, N. G. Pieler, T., and Gruss, P. (1998). Vaxl is a novel homeobox-containing gene expressed in the developing anterior ventral forebrain. Development 125 , 2599-2610.

Hidalgo-Sánchez, M., Martínez-de-laTorre, M., Alvarado-Mallart, R. M., and Puelles, L. (2005). Distinct preisthmic domain, defined by overlap of Otx 2 and Pax 2 expression domains in the chicken caudal midbrain. J. Comp. Neurol. 483, 17-29.

Hoffman, G. E., and Hayes, T. A. (1979). Somatostatin neurons and their projections in dog diencephalon. J. Comp. Neurol. 186, 371-391.

Johansson, O., Hökfelt, T., and Elde, R. P. (1984). Immunohistochemical distribution of somatostatin-like immunoreactivity in the central nervous system of the adult rat. Neuroscience 13, 265-339.

Kimura, S., Hara, Y., Pineau, T. Fernandez-Salguero, P., Fox, C. H., Ward, J. M., and Gonzalez, F. J. (1996). The T/ebp null mouse: thyroid specific enhancer-binding protein is essential for the organogenesis of the thyroid, lung, ventral forebrain, and pituitary. Genes Dev. 10, 60-69.

Lagutin, O. V., Zhu, C. C., Kobayashi, D., Topczewski, J., Shimamura, K., Puelles, L., Russell, H. R. C., McKinnon, P. J., Solnica-Krezel, L., and Oliver, G. (2003). Six3 repression of Wnt signaling in the anterior neuroectoderm is essential for vertebrate forebrain development. Genes Dev. 17, 368-379.

Lechan, R. M., and Fekete, C. (2006). The TRH neuron: a hypothalamic integrator of energy metabolism. Prog. Brain Res. 153, 209-235.

Le Verche, V., Kaindl, A. M., Verney, C., Csaba, Z., Peineau, S., Olivier, P., AdleBiassette, H., Leterrier, C., Vitalis, T. Renaud, J., Dargent, B., and Gressens, P. (2009). The somatostatin $2 \mathrm{~A}$ receptor is enriched in migrating neurons during rat and human brain development and stimulates migration and axonal outgrowth. PLoS ONE4, e5509. doi: 10.1371/journal.pone.0005509

Martí, E., Takada, R., Bumcrot, D. A., Sasaki, H., and McMahon, A. P. (1995). Distribution of Sonic hedgehog peptides in the developing chick and mouse embryo. Development 121 , 2537-2547.

Michaud, J. L. (2001). The developmental program of the hypothalamus and its disorders. Clin. Genet. 60, 255-263.

Nery, S., Fishell, G., and Corbin, J. G. (2002). The caudal ganglionic 
eminence is a source of distinct cortical and subcortical cell populations. Nat. Neurosci. 5, 1279-1287.

Nieuwenhuys, R. (2009). The structural organization of the forebrain: a commentary on the papers presented at the 20th Annual Karger Workshop 'Forebrain Evolution in Fishes'. Brain Behav. Evol. 74, 77-85.

Nieuwenhuys, R., Voogd, J., and van Huijzen, C. (2008). "Development," in The Human Central Nervous System, 4th Edn. (Berlin/Heidelberg: Springer), 55-56.

Pabst, O., Herbrand, H., Takuma, N., and Arnold, H. H. (2000). NKX2 gene expression in neuroectoderm but not in mesendodermally derived structures depends on sonic hedgehog in mouse embryos. Dev. Genes Evol. 210,47-50

Pera, E. M., and Kessel, M. (1997). Patterning of the chick forebrain anlage by the prechordal plate. Development 124, 4153-4162.

Puelles, L. (1995). A segmental morphological paradigm for understanding vertebrate forebrains. Brain Behav. Evol. 46, 319-337.

Puelles, L. (2001). Brain segmentation and forebrain development in amniotes. Brain Res. Bull. 55, 695-710.

Puelles, L., Amat, J. A., and Martínez-Dela-Torre, M. (1987). Segment-related, mosaic neurogenetic pattern in the forebrain and mesencephalon of early chick embryos. I. Topography of AChE-positive neuroblasts up to stage HH18. J. Comp. Neurol. 266, 147-268.

Puelles, L., Kuwana, E., Puelles, E., Bulfone, A., Shimamura, K., Keleher, J., Smiga, S., and Rubenstein, J. L. (2000). Pallial and subpallial derivatives in the embryonic chick and mouse telencephalon, traced by the expression of the genes Dlx-2, Emx-1, Nkx-2.1, Pax-6, and Tbr-1. J. Comp. Neurol.424, 409-438.

Puelles, L., Martinez, S., Martinez-DeLa-Torre, M., and Rubenstein, J. L. (2004). "Gene maps and related histogenetic domains in the forebrain and midbrain," in The Rat Nervous System, 3rd Edn., ed. G. Paxinos (San Diego: Elsevier), 3-25.

Puelles, L., Martínez-de-La-Torre, M., Paxinos, G., Watson, C., and Martinez, S. (2007). The Chick Brain in Stereotaxic Coordinates. An Atlas Featuring Neuromeric Subdivisions and Mammalian Homologies. San Diego: Academic Press-Elsevier.

Puelles, L., and Rubenstein, J. L. (2003). Forebrain gene expression domains and the evolving prosomeric model. Trends Neurosci. 26, 469-476.

Rubenstein, J. L., Shimamura, K. Martinez, S., and Puelles, L. (1998). Regionalization of the prosencephalic neural plate. Annu. Rev. Neurosci. 21, 445-477.

Scanlan, N., Dufourny, L., and Skinner, D. C. (2003). Somatostatin-14 neurons in the ovine hypothalamus: colocalization with estrogen receptor alpha and somatostatin-28(1-12) immunoreactivity, and activation in response to estradiol. Biol. Reprod.69, 1318-1324.

Schwanzel-Fukuda, M., and Pfaff, D. W. (1989). Origin of luteinizing hormone-releasing hormone neurons. Nature 338, 161-164.

Shimada, M., and Nakamura, T. (1973). Time of neuron origin in mouse hypothalamic nuclei. Exp. Neurol. 41, 163-173.

Shimamura, K., Hartigan, D. J., Martinez, S., Puelles, L., and Rubenstein, J. L. (1995). Longitudinal organization of the anterior neural plate and neural tube. Development 121, 3923-3933.

Shimamura, K., and Rubenstein, J. L. (1997). Inductive interactions direct early regionalization of the mouse forebrain. Development 124, 2709-2718.

Shimogori. T., Lee, D. A., MirandaAngulo, A., Yang, Y., Wang, H., Jiang, L., Yoshida, A. C., Kataoka, A., Mashiko, H., Avetisyan, M., Qi, L., Qian, J., and Blackshaw, S. (2010). A genomic atlas of mouse hypothalamic development. Nat. Neurosci. 13, 767-775.

Shiosaka, S., Takatsuki, K., Sakanaka, M., Inagaki, S., Takagi, H., Senba,
E., Kawai, Y., Iida, H., Minagawa, H., Hara, Y., Matsuzaki, T., and Tohyama, M. (1982). Ontogeny of somatostatin-containing neuron system of the rat: immunohistochemical analysis. II. Forebrain and diencephalon. J. Comp. Neurol. 204 211-224.

Shiosaka, S., Takatsuki, K., Sakanaka, M., Inagaki, S., Takagi, H., Senba, E., Kawai, Y., and Tohyama, M. (1981). Ontogeny of somatostatin-containing neuron system of the rat: immunohistochemical observations. I. Lower brainstem. J. Comp. Neurol. 203 , 173-188.

Stühmer, T., Anderson, S. A., Ekker, M., and Rubenstein, J. L. R. (2002). Ectopic expression of the Dlx genes induces glutamic acid decarboxylase and Dlx expression. Development 129 , 245-252.

Vale, W., Rivier, C., Brown, M., and Rivier, J. (1977). Pharmacology of thyrotropin releasing factor (TRF), luteinizing hormone releasing factor (LRF), and somatostatin. Adv. Exp. Med. Biol. 87, 123-156.

Viollet, C., Lepousez, G., Loudes, C. Videau, C., Simon, A., and Epelbaum, J. (2008). Somatostatinergic systems in brain: networks and functions. $\mathrm{Mol}$. Cell. Endocrinol. 286, 75-87.

Wang, W., and Lufkin, T. (2000). The murine Otp homeobox gene plays an essential role in the specification of neuronal cell lineages in the developing hypothalamus. Dev. Biol. 227, 432-449.

Wray, S., Grant, P., and Gainer, H. (1989). Evidence that cells expressing luteinizing hormone-releasing hormone mRNA in the mouse are derived from progenitor cells in the olfactory placode. Proc. Natl. Acad. Sci. U.S.A 86, 8132-8136.

Yacubova, E., and Komuro, H. (2002). Stage-specific control of neuronal migration by somatostatin. Nature 415, 77-81.

Yee, C. L., Wang, Y., Anderson, S., Ekker, M., and Rubenstein, J. L. (2009). Arcuate nucleus expression of NKX2.1 and DLX and lineages expressing these transcription factors in neuropeptide $\mathrm{Y}(+)$, proopiomelanocortin(+), and tyrosine hydroxylase $(+)$ neurons in neonatal and adult mice. J. Comp. Neurol. 517, 37-50.

Zhao, T., Szabó, N., Ma, J., Luo, L., Zhou, X., and Alvarez-Bolado, G. (2008). Genetic mapping of Foxb1-cell lineage shows migration from caudal diencephalon to telencephalon and lateral hypothalamus. Eur. J. Neurosci. 28, 1941-1955.

Zoli, M., Fuxe, K., Agnati, L. F., Härfstrand, A., Terenius, L., Toni, R., and Goldstein, M. (1986). "Computer-assisted morphometry of transmitter-identified neurons: new opening for understanding of peptide-monoamine interactions in the mediobasal hypothalamus," in Neurohistochemistry. Modern Methods and Applications, eds P. Panula, H. Päivarinta, and S. Soimila (New York: Alan R. Liss), 137-174.

Conflict of Interest Statement: The authors declare that the research was conducted in the absence of any commercial or financial relationships that could be construed as a potential conflict of interest.

Received: 01 November 2010; paper pending published: 21 December 2010; accepted: 16 February 2011; published online: 28 February 2011.

Citation: Morales-Delgado N, Merchan P, Bardet SM, Ferrán JL, Puelles L and Díaz C (2011) Topography of somatostatin gene expression relative to molecular progenitor domains during ontogeny of the mouse hypothalamus. Front. Neuroanat. 5:10. doi: 10.3389/fnana.2011.00010 Copyright (c) 2011 Morales-Delgado, Merchan, Bardet, Ferrán, Puelles and Díaz. This is an open-access article subject to an exclusive license agreement between the authors and Frontiers Media SA, which permits unrestricted use, distribution, and reproduction in any medium, provided the original authors and source are credited. 